\title{
BMJ Open A Frailty Instrument for primary care for those aged 75 years or more: findings from the Survey of Health, Ageing and Retirement in Europe, a longitudinal population-based cohort study (SHARE-FI75+)
}

Roman Romero-Ortuno, ${ }^{1,2}$ Christopher Soraghan ${ }^{3,4}$

To cite: Romero-Ortuno R, Soraghan C. A Frailty Instrument for primary care for those aged 75 years or more: findings from the Survey of Health, Ageing and Retirement in Europe, a longitudinal populationbased cohort study (SHARE-FI75+). BMJ Open 2014:4:e006645. doi:10.1136/bmjopen-2014006645

- Prepublication history and additional material is available. To view please visit the journal (http://dx.doi.org/ 10.1136/bmjopen-2014006645).

Received 15 September 2014 Revised 27 November 2014 Accepted 28 November 2014

CrossMark

For numbered affiliations see end of article.

\section{Correspondence to} Dr Roman Romero-Ortuno; roman.romero-ortuno@nhs. net

\section{ABSTRACT}

Objective: To create and validate a frailty assessment tool for community-dwelling adults aged $\geq 75$ years.

Design: Longitudinal, population-based study.

Setting: The Survey of Health, Ageing and Retirement in Europe (SHARE).

Participants: 4001 women and 3057 men aged $\geq 75$ years from the second wave of SHARE. 3325 women and 2587 men had complete information for the frailty indicators: fatigue, low appetite, weakness, observed gait (walking without help, walking with help, chairbound/bedbound, unobserved) and low physical activity.

Main outcome measures: The internal validity of the frailty indicators was tested with latent class analysis, by modelling an underlying variable with three ordered categories. The predictive validity of the frailty classification was tested against 2-year mortality and 4year disability. The mortality prediction of SHARE-FI75+ was compared with that of previously operationalised frailty scales in SHARE (SHARE-FI, 70-item index, phenotype, FRAIL).

Results: In both genders, all frailty indicators significantly aggregated into a three-category ordinal latent variable. After adjusting for baseline age, comorbidity and basic activities of daily living (BADL) disability, the frail had an OR for 2-year mortality of $2.2(95 \% \mathrm{Cl} 1.2$ to 3.8$)$ in women and 4.2 (2.6 to 6.8$)$ in men. The mortality prediction of SHARE-FI75+ was similar to that of the other SHARE frailty scales. By wave $4,49 \%$ of frail women (78 of 159 ) had at least one more limitation with BADL (compared with 18\% of non-frail, 125 of $684 ; p<0.001$ ); in men, these proportions were $39 \%$ (26 of 66 ) and $18 \%$ (110 of $621)$, respectively $(p<0.001)$. A calculator is supplied for point-of-care use, which automatically replicates the frailty classification for any given measurements. Conclusions: SHARE-FI75+ could help frailty case finding in primary care and provide a focus for personalised community interventions. Further validation in trials and clinical programmes is needed.

\section{Strengths and limitations of this study}

- The systematic identification of frailty in people above the age of 75 in primary care is currently on the health policy agenda.

- This study was carried out to create and validate a frailty assessment tool that could be easy to implement in primary care practice.

- The Survey of Health, Ageing and Retirement in Europe (SHARE)-Fl75+ was validated as an age-independent marker of risk for mortality and incident disability.

- An open access calculator is supplied that automatically classifies a participant as non-frail, prefrail or frail given any indicator measurements.

- A future clinical validation of SHARE-FI75+ may enable primary care implementation of frailty case finding with solely self-reported and observational markers not requiring additional equipment or techniques.

\section{INTRODUCTION}

Frailty is "a state of vulnerability to poor resolution of homoeostasis after a stressor event and is a consequence of cumulative decline in many physiological systems during a lifetime." Campbell and Buchner ${ }^{2}$ defined frailty as "a condition or syndrome which results from a multi-system reduction in reserve capacity to the extent that a number of physiological systems are close to, or past, the threshold of symptomatic clinical failure; and as a consequence the frail person is at increased risk of disability and death from minor external stresses." A systematic review of the literature including studies from the UK, the USA, Europe, Australia and Canada estimated that in community-dwelling adults aged 65 and older, the overall prevalence of frailty is 
$10.7 \%$ (95\% CI $10.5 \%$ to $10.9 \%$ ); that prevalence increases with age and is higher in women. ${ }^{3}$

In Europe, by 2060 those aged $65+$ will comprise $30 \%$ of the population, and one person in eight will be aged 80 or more. ${ }^{4}$ In England, around $15 \%$ of the population were aged $\geq 65$ years in 2008 , and this is expected to increase to nearly $25 \%$ during the next two decades, with the fastest growing sector of the population being people aged $>75$ years. ${ }^{5}$ Even so, the association between age and health status is highly variable in the older population: ${ }^{6}$ on the one hand, many community-dwelling older people are in good physical and cognitive health, and often present to primary care practitioners with relatively well-defined problems that can be managed by single interventions and/or organ-specific specialist referral.

On the other hand, other older patients present with less well-defined problems such as subacute functional decline. ${ }^{7}$ These patients may be complex because their presentation can be rooted in multiple factors, including morbidity (eg, physical, cognitive), polypharmacy, psychosocial influences and social vulnerability, in varying degrees and combinations. In primary care, where consultation times and access to multidisciplinary assessments are limited, unravelling that complexity for the first time can prove challenging. This is why these more complex patients often need a comprehensive geriatric assessment (CGA). ${ }^{78}$

CGA is defined as a multidisciplinary diagnostic and intervention process that identifies physical, cognitive, environmental, psychosocial and socioeconomic components that influence an older adult's health. CGA is based on the premise that a systematic and personalised evaluation may identify remediable problems and, by tackling them in a coordinated and holistic manner, the risk of adverse outcomes for the person will be minimised. ${ }^{9}$

CGA can provide important positive impacts on the health of older people, including more thorough diagnoses, improved overall function and reduced premature mortality. ${ }^{10-14}$ These benefits have costs: reflecting its usual interdisciplinary composition, and the time it takes to gather the relevant data, CGA is labour-intensive and not inexpensive. Therefore, from the point of view of both referrers and providers of CGA, it is important to identify those who need it the most, in order to promote equitable access to this important (but finite) expert multidisciplinary resource.

Although no standard criteria have been validated to readily identify patients who are likely to benefit from $\mathrm{CGA},{ }^{9}$ chronological age alone is unlikely to be an effective criterion given the biological heterogeneity of the population of older people. ${ }^{6}$ It has been argued that the concept of frailty, which is an age-independent marker of risk for adverse outcomes, may fit the biopsychosocial model of primary care and provide care commissioners with a focus for targeting resources at an ageing population; ${ }^{15}{ }^{16}$ in addition, it may help avoid age discrimination in the provision of health and social care services for older people. ${ }^{17}$
In 2012, a workshop of the International Association of Gerontology and Geriatrics, the WHO and the French Society of Geriatrics and Gerontology concluded that one of the research priorities for the coming years should be to develop an assessment tool for frailty that can be administered quickly and easily by general practitioners, nurses, pharmacists, home health providers, social workers and other healthcare workers, whereby a positive screen would indicate the need for GCA and design of tailored interventions. ${ }^{18}$ In 2013, a draft report for the UK National Screening Committee concluded that at present there is insufficient evidence to support the implementation of systematic screening in old age to prevent hospitalisation and/or early death; however, the report also highlighted areas for further research including the identification of measurement tools (including frailty assessment tools) which are the best predictors of adverse outcomes in community-dwelling older people. ${ }^{19}$ This echoes calls from clinicians to develop more efficient methods to detect frailty and measure its severity in routine clinical practice, especially in primary care. ${ }^{1}$ Indeed, family physicians need easy-to-use instruments for frailty. ${ }^{20}$

As such, in order to develop instruments for assessing frailty, it is important to clearly identify the definition of frailty and perhaps its subtypes. In its recent draft guidance, the UK National Institute for Health and Care Excellence (NICE) broadly refers to frailty as a situation of high risk of health problems including disability and mortality. ${ }^{21}$ Building around the idea of frailty as an age-independent marker of risk, many definitions of frailty have been proposed over the years, ranging from narrow definitions involving purely physical aspects (ie, physical phenotype) to much broader definitions which, in addition to physical factors (eg, physical signs, comorbidities, disabilities), also include cognitive and psychosocial aspects. ${ }^{32}$ The frailty index based on CGA is an example of the latter approach. ${ }^{23}{ }^{24}$ It is increasingly recognised that rather than being competitive or mutually exclusive, different approaches are complementary and suitable for different purposes or scenarios. ${ }^{25}$

According to the physical phenotype approach, frailty is identified when three or more of the following criteria are present: unintentional weight loss, self-reported exhaustion, weakness (by assessing handgrip strength), slow walking speed and low physical activity. ${ }^{26}$ This approach defines two additional states: prefrail (ie, one or two criteria present) and non-frail (ie, none of the criteria present). According to the biological theory underpinning the frailty phenotype, comorbidity is a risk factor for frailty, and frailty is a precursor of disability. ${ }^{27}{ }^{28} \mathrm{An}$ internal validation of the frailty phenotype using latent class analysis (LCA) showed that the five criteria aggregated statistically into a syndrome. ${ }^{29}$ The phenotype was found to be valid against incident disease, hospitalisation, falls, disability and mortality, all independently of chronological age ${ }^{26}$ The potential usefulness of Fried's phenotypic criteria for screening purposes was 
demonstrated in a randomised controlled trial that assessed the effectiveness of CGA and subsequent intervention in prefrail and frail community-dwelling older people, finding a favourable outcome based on frailty status and the Barthel Index of activities of daily living. ${ }^{30}$

A problem with Fried's definition is that the dichotomisation of individual criteria that are measured on a continuous scale (ie, handgrip strength, walking speed and physical activity) needs to be done retrospectively according to the lowest 20th centile rule, and there are further stratifications. This requires the use of values from a reference population, which may not be available to primary care practitioners. Thus, frailty assessment with the original Fried's criteria is unlikely to be feasible for point-of-care testing in primary care.

Since surrogates for individual frailty phenotype criteria are possible, ${ }^{31}$ the Frailty Instrument for Primary Care of the Survey of Health, Ageing and Retirement in Europe (SHARE-FI) ${ }^{32}$ was developed to provide healthcare practitioners with a phenotypic frailty assessment tool that does not require post hoc calculations and can be scored immediately after an individual assessment, with reference to a large population-based European sample. SHARE-FI is based on a modified phenotypic approach (fatigue, low appetite, weakness by handgrip strength, difficulties walking or climbing stairs and low physical activity) and is intended for communitydwelling Europeans aged $\geq 50$. SHARE-FI is fully noncommercial and its web-based calculators (for each gender) are freely accessible on BMC Geriatrics (http:// www.biomedcentral.com/1471-2318/10/57/additional) ${ }^{32}$ and on https://sites.google.com/a/tcd.ie/share-frailtyinstrument-calculators/.

The five SHARE-FI components have been shown (through LCA) to have internal validity, ${ }^{32} 33$ and the instrument has been validated against incident mortality $^{3435}$ and disability, ${ }^{36}$ independently of chronological age. A consensus group consisting of delegates from six major international, European and US societies referred to SHARE-FI as an example of a well-validated frailty model. ${ }^{37}$ In a systematic review, Pialoux $e t a l^{38}$ compared the properties of 10 frailty screening tools for primary care, and identified SHARE-FI as potentially suitable. In addition, a systematic review by the Oxford Centre for Monitoring and Diagnosis in Primary Care concluded that SHARE-FI may be a good screening instrument. ${ }^{39}$

Even though SHARE-FI has been piloted in clinical settings such as a geriatric day hospital, ${ }^{40}$ an intermediate care rehabilitation facility ${ }^{41}$ and acute hospitals, ${ }^{42}{ }^{43}$ its use in primary care may be less feasible, due to the fact that handgrip strength is not routinely assessed in primary care. In addition, given the considerable variation in methods of assessing grip strength, which can affect the values recorded, ${ }^{44}$ the exact SHARE (Survey of Health, Ageing and Retirement in Europe) grip measurement protocol ${ }^{45}$ needs to be observed for every SHARE-FI measurement. This may be a disincentive for busy general practitioners. In contrast, the detection of slow walking speed has been proposed as an easier approach to the screening of frailty in the primary care setting. ${ }^{46-50}$

In SHARE, those aged 75 years or more were offered an assessment of their walk. ${ }^{51}$ The present study endeavoured to apply the same methodology used for SHARE-FI to create and validate a new frailty assessment tool in SHARE intended for the 75+, based on walking test information as opposed to handgrip strength. If such an instrument had comparable validity (in terms of mortality and disability prediction), it might be easier to implement in primary care practice since it would not require handgrip strength assessment.

\section{METHODS}

\section{Participants}

Participants were women and men aged 75 years or more who were included in the second wave of SHARE (release 2.6.0, as of 29 November 2013), corresponding to nationally representative samples of 14 European countries (Austria, Germany, Sweden, the Netherlands, Spain, Italy, France, Denmark, Greece, Switzerland, Belgium, Czechia, Poland and Ireland). Wave 2 was chosen instead of wave 1 in order to maximise the $75+$ sample size (Czechia, Poland and Ireland did not participate in wave 1: http://www.share-project.org/home0/ overview.html, last accessed: 30 July 2014).$^{52}$ Data for wave 2 were collected between 2006 and 2007.

SHARE aimed at extracting, from each country, probability samples that would allow inferring from the sample to the finite population of Europeans aged 50 and over. The official target population was defined as all individuals born in 1954 or earlier, speaking the official language of the country and not living abroad or in an institution (such as a prison or institution for older people) during the duration of the fieldwork, and their spouses/partners independently of age ${ }^{53}$ For the total pooled sample in wave $1 \quad(\mathrm{~N}=31115)$, country-specific individual response rates ranged between $73.7 \%$ and $93.3 \%$, with an average of $\quad 85.3 \%$ (http://www.share-project.org/data-accessdocumentation/sample.html, last accessed: 30 July 2014).

In wave 2 , respondents from wave 1 were recontacted and a refresher sample was also drawn for all first wave countries (except Austria and the Flemish part of Belgium). For the refresher sample, the same sampling methods were used as in wave 1 ; only cohorts born in 1955 and 1956 were oversampled to keep the sample representative of the population 50 years old and older. ${ }^{54}$

For the prospective validation of SHARE-FI75+, we used the subset of wave 2 participants for whom mortality data at wave 3 were available (wave 3 data were collected in 2008-2009 for all countries except for Ireland: 2009-2010). In addition, we used wave 4 data $^{55} 56$ (2011-2012) to validate the frailty instrument against incident disability. Wave 4 mortality data will not be available until the release of wave 5 data (http://www. share-project.org/home0/wave-5.html, last accessed: 23 August 2014). 


\section{Frailty variables}

The frailty criteria for SHARE-FI75+ were defined as follows:

- Fatigue was identified as a positive answer to the question: "In the last month, have you had too little energy to do the things you wanted to do?" A positive answer (Yes) was recoded as 1 , and No was recoded as 0 . This criterion is the same as in SHARE-FI. ${ }^{32}$

- The low appetite criterion was fulfilled by reporting a "Diminution in desire for food" in response to the question: "What has your appetite been like?" or, in the case of a non-specific or uncodeable response to this question, by responding 'Less' to the question: "So, have you been eating more or less than usual?" The presence of the criterion was coded as 1 and its absence as 0 . This criterion is the same as in SHARE-FI. ${ }^{32}$

-Weakness was defined as a positive answer to either of the following two items: "Because of a health problem, do you have difficulty (expected to last more than 3 months) getting up from chair after sitting for long periods?" or “...lifting or carrying weights over 10 pounds $/ 5$ kilos, like a heavy bag of groceries?" One or two positive answers received the score of 1 , and two negative answers received the score of 0 . The chair-rise question aims to capture lower-body muscle weakness, ${ }^{57}$ and the one on lifting or carrying weights aims to capture upper-body muscle weakness.

- Slowness. In SHARE, only respondents who were 75 years or older were asked to complete a walking test. As per the walking test protocol, ${ }^{58} 59$ the interviewer was asked to record the respondent status beforehand as follows:

- Observed walking without help of another person or using support;

- Observed walking with help of another person or using support;

- Not observed-in wheelchair;

- Not observed-bedbound;

- Not observed-uncertain if respondent has impairment.

For coding the slowness variable, we defined the following subvariables: 'Observed gait,', 'Observed gaito', 'Observed gait ${ }_{3}$ ' and 'Observed gait ${ }_{4}$ '. In the algorithm, only one receives a value equal to 1 , depending on the 'respondent status' recorded. All others receive a value of 0 . For example, selecting the first option ("without help') saw 'Observed gait ${ }_{1}$ ' coded as 1 and all others, that is, 'Observed gait2', 'Observed gaits' and 'Observed gait ${ }_{4}$ ', coded as 0 . Similarly, selecting the second option ('with help') saw 'Observed gait,' coded as 1 and all others coded as 0 . Selecting either the third or fourth option ('not observed-wheelchair or bedbound') saw 'Observed gaits' coded as 1 , and all others coded as 0 . Finally, selecting the fifth option ('not observed-uncertain if impediment') saw 'Observed gait ${ }_{4}$ ' coded as 1 , with all others coded as 0 .
- The low physical activity criterion was assessed by the question: "How often do you engage in activities that require a low or moderate level of energy such as gardening, cleaning the car, or taking a walk?" Responses were coded as follows: $1=$ "More than once a week"; 2="Once a week"; 3=One to three times a month" and 4="Hardly ever or never". This criterion is the same as in SHARE-FI. ${ }^{32}$

\section{Measures for cross-sectional correlations}

Sociodemographic domain:

- Age (years). It was obtained by subtracting the year of birth from 2007.

- No more than primary education: defined as code 0 (preprimary education) or 1 (primary education or first stage of basic education) from the International Standard Classification of Education (ISCED, 1997 version). ${ }^{60}$

Physical domain:

- Poor self-rated health: defined as the choice of 'poor' among the following options: 'excellent', 'very good', 'good', 'fair' and 'poor'.

- Number of chronic diseases: calculated as the sum of affirmative self-reports to the following conditions (if diagnosed by a doctor): (1) heart attack or myocardial infarction or coronary thrombosis or any other heart problem including congestive heart failure; (2) high blood pressure or hypertension; (3) high blood cholesterol; (4) stroke or cerebrovascular disease; (5) diabetes or high blood sugar; (6) chronic lung disease such as chronic bronchitis or emphysema; (7) asthma; (8) arthritis, including osteoarthritis, or rheumatism; (9) osteoporosis; (10) cancer or malignant tumour, including leukaemia or lymphoma, but excluding minor skin cancers; (11) stomach or duodenal ulcer, or peptic ulcer; (12) Parkinson's disease; (13) cataracts; (14) hip fracture or femoral fracture; (15) other fractures; (16) Alzheimer's disease, dementia or senility; (17) benign tumour and (18) other conditions.

- Number of medical symptoms present for at least the past 6 months, from the following list: (1) pain in the back, knees, hips or any other joint; (2) heart trouble or angina, chest pain during exercise; (3) breathlessness, difficulty breathing; (4) persistent cough; (5) swollen legs; (6) sleeping problems; (7) falling down; (8). fear of falling down; (9) dizziness, faints or blackouts; (10) stomach or intestine problems, including constipation, 'air' (flatulence) or diarrhoea; (11) incontinence or involuntary loss of urine; (12) fatigue and (13) other symptoms.

- Number of conditions for which the respondent takes drugs at least once a week, from the following list: (1) drugs for high blood cholesterol; (2) drugs for high blood pressure; (3) drugs for coronary or cerebrovascular diseases; (4) drugs for other heart diseases; (5) drugs for asthma; (6) drugs for diabetes; (7) drugs for joint pain or for joint inflammation; (8) drugs for other pain (eg, headache, back pain, etc); (9) drugs for 
sleep problems; (10) drugs for anxiety or depression; (11) drugs for osteoporosis, hormonal; (12) drugs for osteoporosis, other than hormonal; (13) drugs for stomach burns; (14) drugs for chronic bronchitis and (15) other drugs.

- Number of contacts with a medical doctor in the past 12 months (excluding dentist visits and hospital stays, but including emergency room or outpatient clinic visits).

- Admitted to hospital in the past 12 months (yes or no; includes stays in medical, surgical, psychiatric or in any other specialised wards for at least one night).

Functional domain:

- Number of limitations with basic activities of daily living (BADL, expected to last at least 3 months), from the following list: (1) bathing or showering; (2) dressing, including putting on shoes and socks; (3) using the toilet, including getting up or down; (4) eating, such as cutting up your food and (5) continence (reported as incontinence or involuntary loss of urine for at least the past 6 months). This BADL index is based on the one by Katz el $a l,{ }^{61}$ but does not include functional transfers because they are included in the frailty definition.

- Number of limitations with instrumental activities of daily living (IADL, expected to last at least 3 months), from the following list: (1) making telephone calls; (2) shopping for groceries; (3) preparing a hot meal; (4) doing work around the house or garden; (5) using a map to figure out how to get around in a strange place; (6) taking medications and (7) managing money, such as paying bills and keeping track of expenses. This IADL index is based on the one by Lawton and Brody. ${ }^{62}$

- Received home care for personal or nursing care in the past 12 months: yes or no.

- Received home care for domestic tasks in the past 12 months: yes or no.

Psychological and cognitive domains:

- EURO-D depression scale. ${ }^{63}$

- Verbal fluency test score: maximum number of different animals that the respondent is able to name in $60 \mathrm{~s}$.

- Delayed word recall: maximum number of words (out of a list of 10) that the respondent is able to recall after an initial recall followed by verbal fluency and numeracy tests.

\section{Measures for prospective validation}

The release of wave 2 data contains a variable that informs whether respondents were still alive in wave 3 , deceased between wave 2 and wave 3, or with missing mortality information (ie, 2-year mortality data). Disability information (BADL and IADL) was sought for wave 2 respondents who were also included in wave 4 (ie, 4-year disability data).

\section{Statistical analyses}

Univariate descriptives

Individual variable descriptives were given as mean and $\mathrm{SD}$ or proportion (\%) as appropriate.
Level of significance

It was set at $\mathrm{p}<0.01$ throughout.

\section{Missing frailty phenotype data}

Besides the explicit coding of unobserved walking ability, missing data for all other items of the phenotype were treated as missing (ie, not given an explicit code).

\section{Internal validation of the frailty measure}

In order to assess whether the criteria composing the frailty measure aggregated statistically into a syndrome, we estimated (for each gender) a discrete factor (DFactor) model using the LatentGOLD (V.5.0) latent class modelling package (http://www.statisticalinnovations.com). A single DFactor with three ordered levels (non-frail, prefrail and frail) was requested. Each DFactor model included age as a covariate. This procedure is the same as was previously done for SHARE-FI. ${ }^{32}$

The outputs from LatentGOLD (V.5.0) are as follows: (1) loading of each frailty indicator on the underlying DFactor and its significance level; (2) frailty categories as per the DFactor model (ie, non-frail, prefrail and frail); (3) continuous frailty score as per the DFactor model and (4) full DFactor syntax for scoring new cases given any frailty measurements. For each gender, the LatentGOLD outputs were saved in the IBM SPSS Statistics (V.20.0) format and merged with the SHARE waves 2 and 4 data sets to allow for cross-sectional and longitudinal correlations.

\section{Correlations of the frailty categories with SHARE wave 2 variables}

The two-tailed Spearman's rank correlation (r) coefficient was used to correlate the (ordinal) frailty category variable with continuous and ordinal variables; these correlations were controlled for age using the SPSS partial correlations procedure. The $\chi^{2}$ for trend was used to test the association between the frailty variable and dichotomous variables; to control for the effects of age, ordinal regression was used (with the frailty variable as the dependent variable).

\section{Analysis of missing mortality data}

For each gender, comparisons between mortalityavailable and mortality-unavailable groups were conducted with the $\chi^{2}$ test (for dichotomous variables) or the Mann-Whitney U test (for continuous or ordinal variables).

\section{Prospective validation}

Binary logistic regression was conducted to assess whether the ordinal frailty variable significantly predicted whether or not a participant was deceased by wave 3. Three models were computed: an unadjusted model (model 1), a model controlling for age (model 2) and one that also controlled for the number of chronic diseases and limitations with BADL (model 3). 
The 4-year disability outcome was defined as an increase of $\geq 1$ BADL or IADL disability between waves 2 and 4 .

\section{Comparison of SHARE-FI75+ with SHARE-FI and other SHARE frailty scales}

In order to compare SHARE-FI75+ and SHARE-FI ${ }^{32}$ in their ability to predict 2-year mortality and 4-year disability, the SHARE-FI frailty categories and continuous score were computed on the SHARE-FI75+ sample using the published formulae. ${ }^{32}$ The comparison of proportions between SHARE-FI75+ and SHARE-FI categories were conducted with the two-tailed $\mathrm{z}$ test (http://www. socscistatistics.com/tests/ztest/Default.aspx, last accessed 23 August 2014). In addition, the mortalities associated with the continuous frailty score of both instruments were compared using receiver operating characteristic (ROC) curves (IBM SPSS Statistics, V.20.0). Comparative mortality analyses were also carried out with the following additional SHARE frailty scales:

- 70-item SHARE Frailty Index (70-SHARE-FIx): an index was constructed using 70 measures from the physical health, behavioural risks, cognitive function and mental health sections of the SHARE wave 2 survey. This 70-item index is identical to the one previously operationalised by Theou et al. ${ }^{3464}$

- SHARE FRAIL scale (SHARE-FRAIL): this scale was developed as an easy screening tool by Morley and colleagues, ${ }^{65}$ and was also adapted to SHARE by Theou et al. ${ }^{34} 64$

- SHARE frailty phenotype (unweighted; SHARE-FP): in SHARE-FI ${ }^{32}$ and SHARE-FI75+, the cut-offs for the phenotypic categories (ie, non-frail, prefrail and frail) are automatically derived from LCA, while the original unweighted Fried's frailty phenotype (as operationalised in SHARE by Santos-Eggimann $e t a l^{66}$ ) uses a rule based on the number of criteria present: $\geq 3$ : frail; 1 or 2: prefrail; 0 : non-frail. ${ }^{67}$

\section{Construction of the SHARE-FI75+ calculator}

The SHARE-FI75+ interface was designed using Microsoft Excel 2010. The DFactor syntax (male and female models) from LatentGOLD (V.5.0; viewed in SPSS) was translated into Microsoft Excel formulae to compute the frailty score and categories (ie, non-frail, prefrail and frail). The bespoke spreadsheet was then converted to a HTML/Javascript form (webpage) using a plug-in converter for Excel (SpreadSheetconverter V.7.7.6036, Framtidsforum I \& M AB, Uppsala Sweden, 2002-2014, http://www.spreadsheetconverter.com). A single form was constructed rather than a separate one for each gender, which was the case for SHARE-FI. For this, an initial question on 'gender' is asked to determine which algorithm to use. Note: the technical formulae are described in the online supplementary technical appendix.

\section{Ethics approval}

We undertook a secondary analysis of data obtained under the SHARE Data Access Rules (http://share-dev. mpisoc.mpg.de/data-access-documentation/research-datacenter-data-access.html). All participants gave informed consent before taking part in the study.

\section{Sources of funding}

This paper uses data from SHARE wave 4 release 1.1.1, as of 28 March 2013, and SHARE wave 2 release 2.6.0, as of 29 November 2013. The SHARE data collection has been primarily funded by the European Commission through the fifth Framework Programme (project QLK6-CT-2001-00360 in the thematic programme Quality of Life), through the sixth Framework Programme (projects SHARE-I3, RII-CT-2006-062193, COMPARE, CIT5-CT-2005-028857, and SHARELIFE, CIT4-CT-2006-028812) and through the seventh Framework Programme (SHARE-PREP, $\mathrm{N}^{\circ}$ 211909, SHARE-LEAP, $\mathrm{N}^{\circ} 227822$ and SHARE M4, $\mathrm{N}^{\circ}$ 261982). Additional funding from the US National Institute on Aging (U01 AG09740-13S2, P01 AG005842, P01 AG08291, P30 AG12815, R21 AG025169, Y1-AG-4553-01, IAG BSR06-11 and OGHA 04-064) and the German Ministry of Education and Research as well as from various national sources is gratefully acknowledged (see http://www.share-project.org for a full list of funding institutions).

\section{Statement of independence from funders}

The SHARE funding organisations had no role in the study design; in the collection, analysis and interpretation of data; in the writing of the report; or in the decision to submit the article for publication. RR-O and CS are independent from the SHARE funding organisations.

\section{Data sharing statement}

We undertook a secondary analysis of data obtained under the SHARE Data Access Rules (http://share-dev. mpisoc.mpg.de/data-access-documentation/research-datacenter-data-access.html). SHARE data can be accessed by anyone who abides by those rules. No additional data are available from the authors.

\section{RESULTS}

In total, 4001 women and 3057 men aged 75 years or more were included in the second wave of SHARE. The mean age (SD) of women was 81.1 (4.9), and that of men was 80.4 (4.6). Figure 1 shows the participants' flow chart.

\section{Estimation of the frailty models}

Descriptive statistics for the SHARE-FI75+ variables (by gender) are reported in table 1 . The proportion of missing data for the walking speed test $(49.5 \%$ in women and $44.2 \%$ in men) was deemed unacceptably high; this is why the observed 'respondent status' was used as a surrogate low walking speed criterion (the 


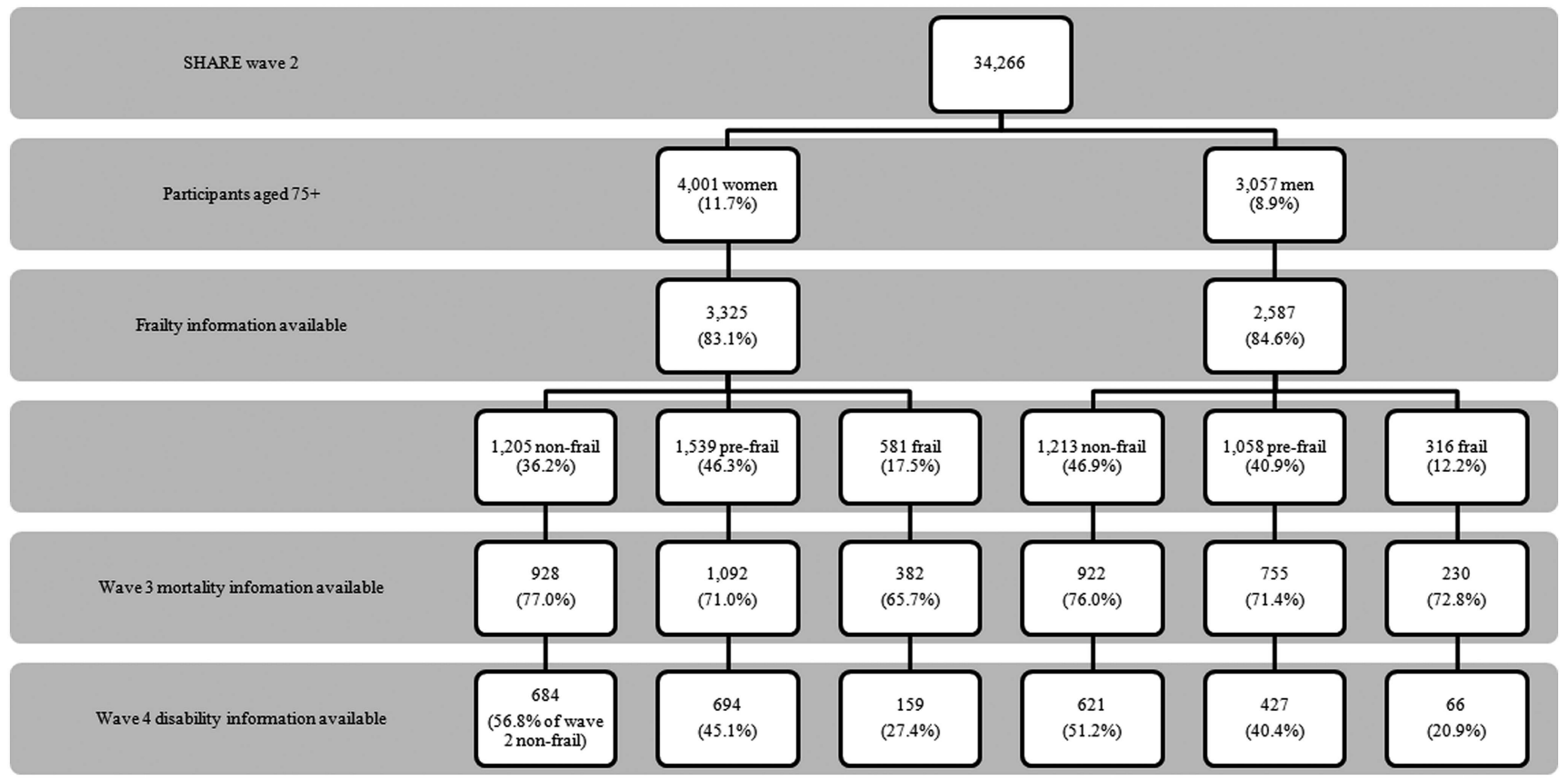

Figure 1 Participants' flow chart (SHARE, the Survey of Health, Ageing and Retirement in Europe).

proportion of missing information was $12.1 \%$ in women and $12.7 \%$ in men). All other frailty variables had a proportion of missing data of $<5 \%$ (table 1 ). Complete data for the estimation of the frailty models were available for 3325 women $(83.1 \%)$ and 2587 men $(84.6 \%)$.

Frailty model for women

The DFactor model included 3325 cases. Nineteen parameters were estimated, standard $R^{2}=0.69$, entropy $R^{2}=0.51$.
All frailty indicators discriminated well $(\mathrm{p}<0.001)$ between the three classes: non-frail $(\mathrm{N}=1205 ; 36.2 \%)$, prefrail $(\mathrm{N}=1539 ; 46.3 \%)$ and frail $(\mathrm{N}=581 ; 17.5 \%)$. The following were the loadings on the DFactor:

- Fatigue $=0.39\left(\mathrm{R}^{2}=0.15\right)$;

- Low appetite $=0.28 \quad\left(\mathrm{R}^{2}=0.08\right)$;

- Weakness $=0.56\left(\mathrm{R}^{2}=0.34\right)$;

- Observed gait $=0.48\left(\mathrm{R}^{2}=0.26\right)$;

- Frequency of activities $=0.65 \quad\left(\mathrm{R}^{2}=0.43\right)$.

Table 1 Descriptive statistics for the SHARE-FI75+ variables (by gender)

\begin{tabular}{|c|c|c|c|c|c|c|}
\hline & \multicolumn{3}{|c|}{ Women $(\mathrm{N}=4001)$} & \multicolumn{3}{|l|}{ Men $(\mathrm{N}=3057)$} \\
\hline & $\begin{array}{l}\mathrm{N} \text { with } \\
\text { measurement } \\
\text { available }\end{array}$ & $\begin{array}{l}\text { Descriptive } \\
\text { statistic }\end{array}$ & $\begin{array}{l}\text { Per cent } \\
\text { missing }\end{array}$ & $\begin{array}{l}\mathrm{N} \text { with } \\
\text { measurement } \\
\text { available }\end{array}$ & $\begin{array}{l}\text { Descriptive } \\
\text { statistic }\end{array}$ & $\begin{array}{l}\text { Per cent } \\
\text { missing }\end{array}$ \\
\hline Fatigue (\%) & 3841 & 49.4 & 4.0 & 2971 & 38.8 & 2.8 \\
\hline Low appetite (\%) & 3862 & 16.4 & 3.5 & 2987 & 11.9 & 2.3 \\
\hline Weakness (\%) & 3980 & 60.7 & 0.5 & 3044 & 38.6 & 0.4 \\
\hline \multicolumn{7}{|c|}{ Respondent status for the walk test } \\
\hline Unaided (\%) & 3515 & 70.6 & 12.1 & 2668 & 77.7 & 12.7 \\
\hline Aided (\%) & & 17.8 & & & 11.4 & \\
\hline Chair/bedbound (\%) & & 4.3 & & & 3.3 & \\
\hline Not observed (\%) & & 7.3 & & & 7.5 & \\
\hline $\begin{array}{l}\text { Walking speed, seconds: } \\
\text { mean (SD) }\end{array}$ & 2019 & $5.0(3.9)$ & 49.5 & 1707 & $4.4(3.8)$ & 44.2 \\
\hline \multicolumn{7}{|l|}{ Low physical activity } \\
\hline More than weekly (\%) & 3861 & 47.5 & 3.5 & 3006 & 58.9 & 1.7 \\
\hline Once weekly (\%) & & 12.9 & & & 11.6 & \\
\hline 1-3 monthly (\%) & & 6.9 & & & 6.5 & \\
\hline Hardly ever/never (\%) & & 32.8 & & & 23 & \\
\hline
\end{tabular}




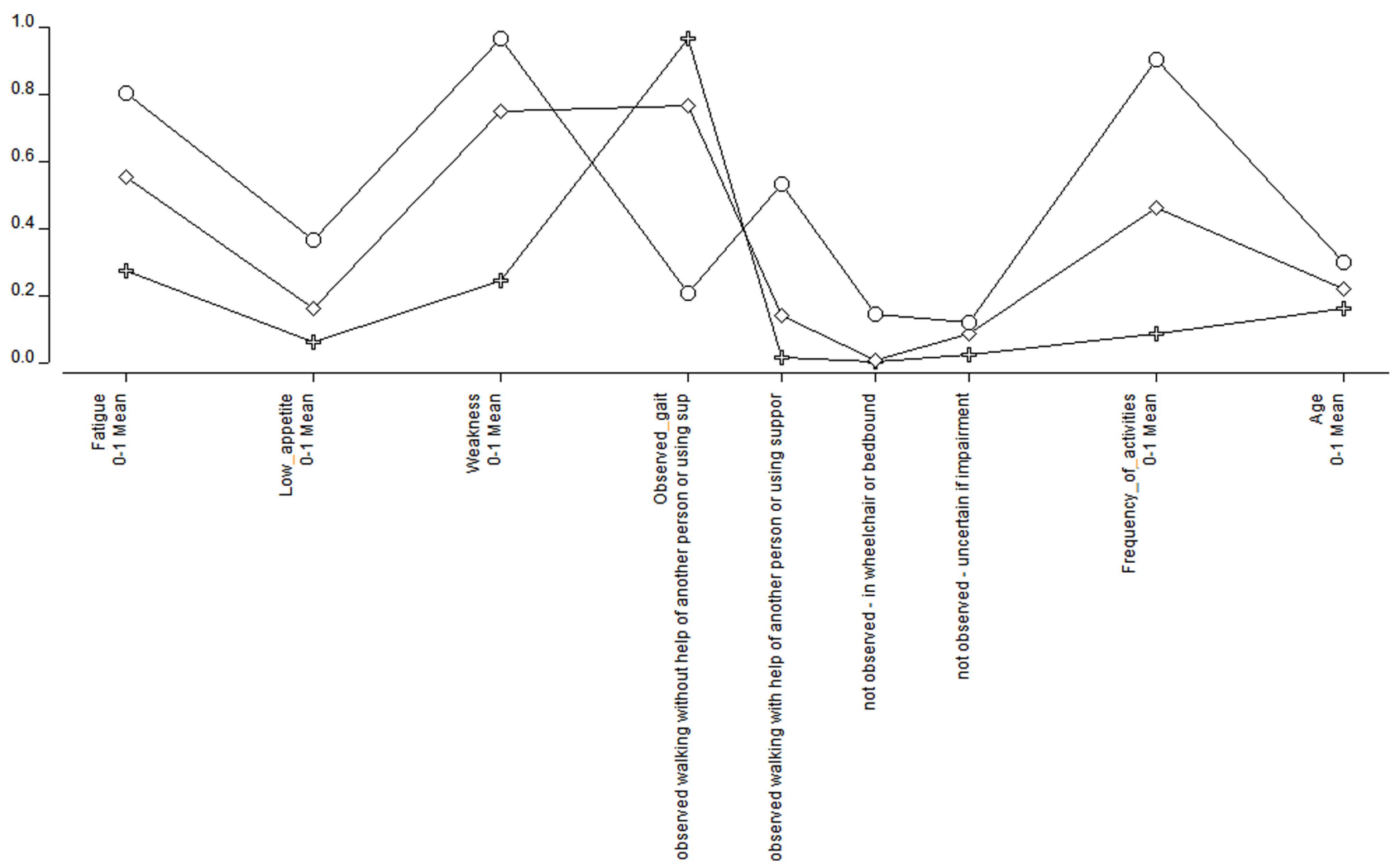

Figure 2 Frailty model for women (LatentGOLD V.5.0 output). The line joined by crosses represents the non-frail category; the line joined by squares represents the prefrail category; and the line joined by circles represents the frail category. The $Y$ axis represents the posterior probability for each frailty variable in each frailty category.

Figure 2 (from the output of LatentGOLD V.5.0) shows the conditional probabilities (given class membership) for the frailty model in women.

\section{Frailty model for men}

The DFactor model included 2587 cases. Nineteen parameters were estimated, standard $R^{2}=0.68$, entropy $R^{2}=0.50$. All frailty indicators discriminated well $(\mathrm{p}<0.001)$ between the three classes: non-frail $(\mathrm{N}=1213 ; 46.9 \%)$, prefrail $(\mathrm{N}=1058 ; 40.9 \%)$ and frail $(\mathrm{N}=316 ; 12.2 \%)$. The following were the loadings on the DFactor:

- Fatigue $=0.45\left(\mathrm{R}^{2}=0.20\right)$;

- Low appetite $=0.32\left(\mathrm{R}^{2}=0.12\right)$;

- Weakness $=0.62\left(\mathrm{R}^{2}=0.38\right)$;

- Observed gait=0.43 $\left(\mathrm{R}^{2}=0.22\right)$;

- Frequency of activities=0.60 $\left(\mathrm{R}^{2}=0.36\right)$.

Figure 3 shows the conditional probabilities (given class membership) for the frailty model in men.

\section{Cross-sectional correlations}

These are reported in table 2. Our results support that all age-adjusted cross-sectional correlations were statistically significant. For both women and men, results were compatible with a biopsychosocial gradient, in the expected direction, across the frailty categories.

\section{Prediction of mortality}

Wave 3 mortality data were available for 2402 women (72.2\% of wave 2 participants with frailty information) and 1907 men $(73.1 \%)$. Tables 3 (women) and 4 (men) report the differences between mortality-available and mortality-unavailable subgroups. Wave 2 women with no wave 3 mortality data were significantly older and more frail than those with mortality data (table 3 ). In men (table 4), the differences were less marked but still compatible with no mortality data being associated with older age, unobserved gait status and less likelihood of being able to walk without help (table 4).

As reported in table 2, the 2-year mortality rates in women were $2.4 \%$ for the non-frail category, $5.3 \%$ for the prefrail category and $13.4 \%$ for the frail category. In men, the 2-year mortality rates were $3.9 \%$ for the non-frail category, $9.2 \%$ for the prefrail category and $26.3 \%$ for the frail category. Model 3 results are compatible with these mortality associations being independent of baseline age, number of chronic diseases and number of BADL limitations.

\section{Prediction of disability}

Wave 4 disability data were available for 1537 women (46.2\% of the wave 2 sample with frailty information) and 1114 men $(43.1 \%)$. Table 2 results are compatible with a gradient of increasing disability (as also seen in wave 2) across frailty categories. Results also suggest that the proportion of at least one more disability between waves 2 and 4 increased across frailty categories, for both BADL and IADL, independently of age. 


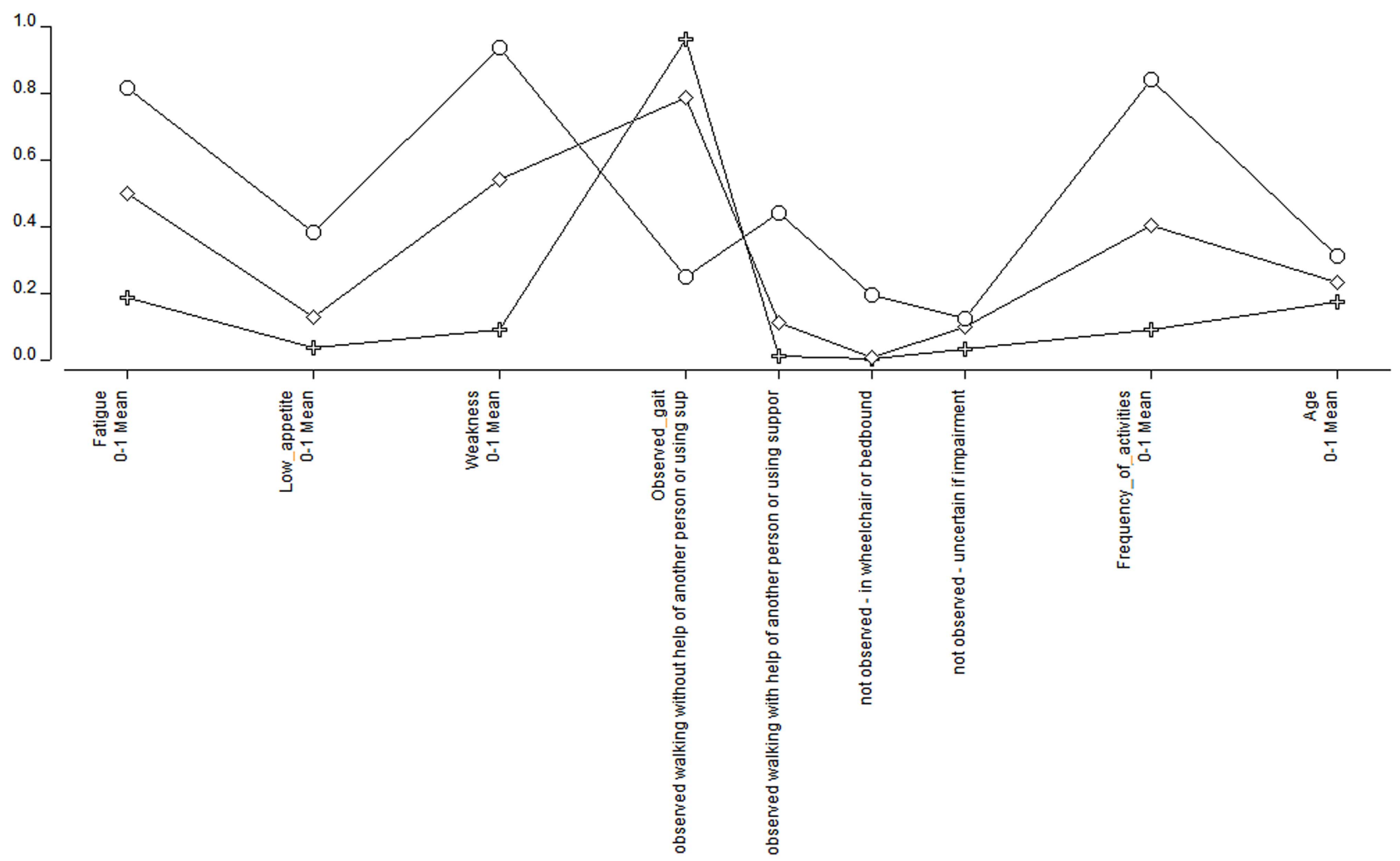

Figure 3 Frailty model for men (LatentGOLD V.5.0 output). The line joined by crosses represents the non-frail category; the line joined by squares represents the prefrail category; and the line joined by circles represents the frail category. The $\mathrm{Y}$ axis represents the posterior probability for each frailty variable in each frailty category.

\section{Comparison of SHARE-FI75+ with SHARE-FI and other SHARE frailty scales}

Results in table 2 suggest that the 2-year mortality prediction by SHARE-FI75+ was not inferior to that of SHARE-FI, judging by the non-significant $\mathrm{z}$ statistics. The ROC curves representing the mortality associated with the continuous scores of SHARE-FI, SHARE-FI75+, 70-SHARE-FIx, SHARE-FRAIL and SHARE-FP are compared in figures 4 (women) and 5 (men).

Results in table 2 suggest that the 4-year disability prediction was stronger with SHARE-FI75+ for prefrail women only (for both BADL and IADL); otherwise, no statistically significant differences were seen between SHARE-FI75+ and SHARE-FI.

\section{Frailty calculator}

The Excel and HTML versions of the SHARE-FI75+ calculator are supplied as online supplementary files. The syntax for the calculator is detailed in the online supplementary technical appendix.

\section{DISCUSSION}

This study created and validated a new phenotypic frailty assessment tool intended for the $75+$ and based on a large European population-based sample. SHARE-FI75+ could be administered quickly and easily by general practitioners, nurses, pharmacists, home health providers, social workers and other healthcare workers, in order to help indicate and prioritise the need for GCA and design of tailored interventions. ${ }^{18}$ SHARE-FI75+ is a fully noncommercial, open access tool intended to facilitate the identification of frailty in community and primary care settings and promote the equity of access to specialised geriatric services.

The internal validation of SHARE-FI75+ using LCA suggested that all its items significantly aggregated into an underlying (unobserved) variable with three ordered categories (ie, non-frail, prefrail and frail), in keeping with the phenotype theory. ${ }^{26}$ For both women and men, the cross-sectional correlates of SHARE-FI75+ were compatible with a biopsychosocial gradient, in the expected direction, across the frailty categories. SHARE-FI75+ predicted mortality independently of baseline age, comorbidity and BADL disability; SHARE-FI75+ was also positively associated with disability gain at 4 years, independently of age. These validation results are in keeping with the theory that chronological age, comorbidity, disability and frailty are distinct clinical entities that are causally related. ${ }^{28}$

For the development of SHARE-FI75+, we included one variable for each item of the frailty phenotype and four subvariables for the 'walking' item. Mortality comparison with a 70-item frailty index suggested that an increase in the number of items in the frailty definition did not significantly improve the prediction of the test. 


\begin{tabular}{|c|c|c|c|c|c|c|c|c|c|c|}
\hline & \multicolumn{5}{|c|}{ Women $(\mathrm{N}=3325)$} & \multicolumn{5}{|c|}{ Men $(\mathrm{N}=2587)$} \\
\hline & $\begin{array}{l}\text { Non-frail } \\
(\mathrm{N}=1205) \\
(36.2 \%)\end{array}$ & $\begin{array}{l}\text { Prefrail } \\
(N=1539) \\
(46.3 \%)\end{array}$ & $\begin{array}{l}\text { Frail }(\mathrm{N}=581) \\
(17.5 \%)\end{array}$ & p Value & $\begin{array}{l}\text { Age-adjusted } \\
\mathrm{p} \text { value }\end{array}$ & $\begin{array}{l}\text { Non-frail } \\
(\mathrm{N}=1213) \\
(46.9 \%)\end{array}$ & $\begin{array}{l}\text { Prefrail } \\
(\mathrm{N}=1058) \\
(40.9 \%)\end{array}$ & $\begin{array}{l}\text { Frail }(\mathrm{N}=316) \\
(12.2 \%)\end{array}$ & $p$ Value & $\begin{array}{l}\text { Age-adjusted } \\
\mathrm{p} \text { value }\end{array}$ \\
\hline \multicolumn{11}{|l|}{ Frailty phenotype: DFactor model } \\
\hline Fatigue: yes (cp) & 0.27 & 0.55 & 0.80 & - & $<0.001^{*}$ & 0.18 & 0.50 & 0.81 & - & $<0.001^{*}$ \\
\hline Low appetite: yes (cp) & 0.06 & 0.16 & 0.36 & - & $<0.001^{\star}$ & 0.03 & 0.13 & 0.38 & - & $<0.001^{\star}$ \\
\hline Weakness: yes (cp) & 0.24 & 0.75 & 0.96 & - & $<0.001^{*}$ & 0.09 & 0.54 & 0.94 & - & $<0.001^{*}$ \\
\hline Observed walking without help (cp) & 0.97 & 0.77 & 0.21 & - & $<0.001^{*}$ & 0.96 & 0.79 & 0.25 & - & $<0.001^{*}$ \\
\hline Observed walking with help (cp) & 0.01 & 0.14 & 0.53 & - & $<0.001^{\star}$ & 0.01 & 0.11 & 0.44 & - & $<0.001^{\star}$ \\
\hline Observed in wheelchair/bedbound (cp) & $<0.01$ & 0.01 & 0.14 & - & $<0.001^{*}$ & $<0.01$ & 0.01 & 0.19 & - & $<0.001^{*}$ \\
\hline Gait not observed (cp) & 0.02 & 0.09 & 0.12 & - & $<0.001^{*}$ & 0.03 & 0.10 & 0.12 & - & $<0.001^{\star}$ \\
\hline Low activity: hardly ever, or never (cp) & 0.03 & 0.34 & 0.83 & - & $<0.001^{*}$ & 0.03 & 0.29 & 0.75 & - & $<0.001^{\star}$ \\
\hline \multicolumn{11}{|l|}{ Sociodemographic } \\
\hline Age: mean (SD) & $79.6(3.5)$ & $81.7(4.4)$ & $84.2(5.4)$ & $<0.001 \dagger$ & - & $79.7(3.5)$ & $81.4(4.3)$ & $83.7(5.4)$ & $<0.001 \dagger$ & - \\
\hline No more than primary education (\%) & 43.6 & 59.5 & 70.5 & $<0.001 \ddagger$ & $<0.001 \S$ & 36.9 & 47.4 & 59.2 & $<0.001 \ddagger$ & $<0.001 \S$ \\
\hline \multicolumn{11}{|l|}{ Physical } \\
\hline Poor self-rated health (\%) & 3.4 & 21.3 & 52.5 & $<0.001 \ddagger$ & $<0.001 \S$ & 3.8 & 21.4 & 55.4 & $<0.001 \ddagger$ & $<0.001 \S$ \\
\hline Number of chronic diseases: mean (SD) & $1.9(1.4)$ & $2.7(1.7)$ & $3.1(1.8)$ & $<0.001 \dagger$ & $<0.0019$ & $1.6(1.3)$ & $2.4(1.6)$ & $2.8(1.6)$ & $<0.001 \dagger$ & $<0.0019$ \\
\hline Number of symptoms: mean (SD) & $1.6(1.6)$ & $3.3(2.3)$ & $4.4(2.5)$ & $<0.001 \dagger$ & $<0.0019$ & $1.2(1.3)$ & $2.6(2.0)$ & $3.8(2.2)$ & $<0.001 \dagger$ & $<0.0019$ \\
\hline $\begin{array}{l}\text { Number of conditions for which takes } \\
\text { drugs (SD) }\end{array}$ & $1.7(1.3)$ & $2.7(1.7)$ & $3.3(1.9)$ & $<0.001 \dagger$ & $<0.001 \emptyset$ & $1.5(1.3)$ & $2.3(1.6)$ & $3.0(1.8)$ & $<0.001 \dagger$ & $<0.001 \rrbracket$ \\
\hline $\begin{array}{l}\text { Number of contacts with doctor in past year: } \\
\text { mean (SD) }\end{array}$ & $6.0(6.9)$ & $9.7(10.3)$ & $11.9(13.7)$ & $<0.001 \dagger$ & $<0.001 \emptyset$ & $6.1(7.4)$ & $9.4(10.3)$ & $14.5(18.1)$ & $<0.001 \dagger$ & $<0.001 \emptyset$ \\
\hline Admitted to hospital in past year (\%) & 12.4 & 23.7 & 32.4 & $<0.001 \ddagger$ & $<0.001 \S$ & 13.9 & 24.6 & 35.8 & $<0.001 \ddagger$ & $<0.001$ § \\
\hline \multicolumn{11}{|l|}{ Functional } \\
\hline Number of limitations with BADL: mean (SD) & $0.1(0.3)$ & $0.5(0.9)$ & $1.8(1.5)$ & $<0.001 \dagger$ & $<0.0019$ & $0.1(0.3)$ & $0.4(0.8)$ & $1.7(1.5)$ & $<0.001 \dagger$ & $<0.0019$ \\
\hline Number of limitations with IADL: mean (SD) & $0.2(0.5)$ & $1.0(1.4)$ & $3.2(2.2)$ & $<0.001 \dagger$ & $<0.0019$ & $0.1(0.5)$ & $0.8(1.3)$ & $3.1(2.3)$ & $<0.001 \dagger$ & $<0.001 \rrbracket$ \\
\hline Received home care: personal/nursing (\%) & 3.8 & 9.5 & 28.3 & $<0.001 \ddagger$ & $<0.001 \S$ & 3.4 & 7.5 & 23.4 & $<0.001 \ddagger$ & $<0.001 \S$ \\
\hline Received home care: domestic tasks (\%) & 7.6 & 21.7 & 34.3 & $<0.001 \ddagger$ & $<0.001 \S$ & 4.8 & 11.1 & 26.6 & $<0.001 \ddagger$ & $<0.001 \S$ \\
\hline \multicolumn{11}{|l|}{ Psychological and cognitive } \\
\hline $\begin{array}{l}\text { EURO-D score (minimum: } 0 \\
\text { maximum: 12) (SD) }\end{array}$ & $1.9(1.7)$ & $3.6(2.4)$ & $5.5(2.8)$ & $<0.001 \dagger$ & $<0.001\rceil$ & $1.4(1.6)$ & $2.8(2.1)$ & $5.2(2.7)$ & $<0.001 \dagger$ & $<0.0019$ \\
\hline Verbal fluency test score: mean (SD) & $16.8(7.0)$ & $14.1(7.7)$ & $10.6(5.7)$ & $<0.001 \dagger$ & $<0.001 \rrbracket$ & $17.0(6.6)$ & $14.9(6.4)$ & $10.6(5.6)$ & $<0.001 \dagger$ & $<0.001 \rrbracket$ \\
\hline Delayed word recall score: mean (SD) & $2.9(1.9)$ & $2.1(1.8)$ & $1.4(1.6)$ & $<0.001 \dagger$ & $<0.001 \rrbracket$ & $2.6(1.8)$ & $2.1(1.7)$ & $1.3(1.4)$ & $<0.001 \dagger$ & $<0.001 \rrbracket$ \\
\hline \multicolumn{11}{|l|}{ Mortality at wave 3: SHARE-FI75+ } \\
\hline $\mathrm{N}$ from wave 2 & 928 & 1092 & 382 & - & - & 922 & 755 & 230 & - & - \\
\hline Per cent dead & 2.4 & 5.3 & 13.4 & $<0.001 \ddagger$ & $<0.001 \S$ & 3.9 & 9.2 & 26.3 & $<0.001 \ddagger$ & $<0.001 \S$ \\
\hline Model 1: unadjusted OR for mortality $(95 \% \mathrm{Cl})$ & 1.0 & 2.3 (1.5 to 3.5$)$ & 6.3 (4.1 to 9.8$)$ & - & - & 1.0 & 2.5 (1.7 to 3.6$)$ & $8.8(6.0$ to 13.0$)$ & - & - \\
\hline $\begin{array}{l}\text { Model 2: age-adjusted OR for mortality } \\
(95 \% \mathrm{Cl})\end{array}$ & 1.0 & $1.9(1.2$ to 2.9$)$ & $4.1(2.6$ to 6.5$)$ & - & - & 1.0 & $2.2(1.6$ to 3.2$)$ & $6.9(4.6$ to 10.3$)$ & - & - \\
\hline Model 3 & 1.0 & $1.7(1.1-2.7)$ & $2.2(1.2-3.8)$ & - & - & 1.0 & $1.9(1.3-2.8)$ & $4.2(2.6-6.8)$ & - & - \\
\hline \multicolumn{11}{|l|}{ Mortality at Wave 3: SHARE-FI } \\
\hline $\mathrm{N}$ from Wave 2 & 657 & 1254 & 374 & - & - & 1141 & 622 & 212 & - & - \\
\hline$\%$ dead & 1.9 & 4.3 & 9.7 & $<0.001 \ddagger$ & $<0.001 \S$ & 4.0 & 6.7 & 25.1 & $<0.001 \ddagger$ & $<0.001 \S$ \\
\hline Model 1: unadjusted OR for mortality $(95 \% \mathrm{Cl})$ & 1.0 & $2.4(1.4$ to 4.1$)$ & 5.6 (3.2 to 9.9$)$ & - & - & 1.0 & $1.7(1.2$ to 2.5$)$ & $8.1(5.6$ to 11.8$)$ & - & - \\
\hline $\begin{array}{l}\text { Model 2: age-adjusted OR for mortality } \\
(95 \% \mathrm{Cl})\end{array}$ & 1.0 & 2.0 (1.2 to 3.5$)$ & $3.9(2.2$ to 7.0$)$ & - & - & 1.0 & 1.6 (1.1 to 2.3$)$ & $6.6(4.5$ to 9.8$)$ & - & - \\
\hline Model 3 & 1.0 & $2.0(1.1-3.5)$ & $3.0(1.6-5.7)$ & - & - & 1.0 & $1.5(1.0-2.2)$ & $5.6(3.6-8.7)$ & - & - \\
\hline
\end{tabular}




\begin{tabular}{|c|c|c|c|c|c|c|c|c|c|c|}
\hline & \multicolumn{5}{|c|}{ Women $(\mathrm{N}=3325)$} & \multicolumn{5}{|c|}{ Men $(\mathrm{N}=2587)$} \\
\hline & $\begin{array}{l}\text { Non-frail } \\
(\mathrm{N}=1205) \\
(36.2 \%)\end{array}$ & $\begin{array}{l}\text { Prefrail } \\
(\mathrm{N}=1539) \\
(46.3 \%)\end{array}$ & $\begin{array}{l}\text { Frail }(\mathrm{N}=581) \\
(17.5 \%)\end{array}$ & $p$ Value & $\begin{array}{l}\text { Age-adjusted } \\
\mathrm{p} \text { value }\end{array}$ & $\begin{array}{l}\text { Non-frail } \\
(\mathrm{N}=1213) \\
(46.9 \%)\end{array}$ & $\begin{array}{l}\text { Prefrail } \\
(N=1058) \\
(40.9 \%)\end{array}$ & $\begin{array}{l}\text { Frail }(\mathrm{N}=316) \\
(12.2 \%)\end{array}$ & $p$ Value & $\begin{array}{l}\text { Age-adjusted } \\
\mathrm{p} \text { value }\end{array}$ \\
\hline \multicolumn{11}{|l|}{ Disability at wave 4: SHARE-FI75+ } \\
\hline $\mathrm{N}$ from wave 2 & 684 & 694 & 159 & - & - & 621 & 427 & 66 & - & - \\
\hline Number of limitations with BADL: mean (SD) & $0.4(0.8)$ & $1.1(1.3)$ & $2.2(1.7)$ & $<0.001 \dagger$ & $<0.0019$ & $0.4(0.9)$ & $0.9(1.3)$ & $1.6(1.6)$ & $<0.001 \dagger$ & $<0.001 \rrbracket$ \\
\hline $\begin{array}{l}\text { Increase in BADL disability from wave } 2 \text { : at } \\
\text { least } 1 \text { point }(\%)\end{array}$ & 18.3 & 39.7 & 49.1 & $<0.001 \ddagger$ & $<0.001 \S$ & 17.7 & 33.7 & 38.5 & $<0.001 \ddagger$ & $<0.001 \S$ \\
\hline Number of limitations with IADL: mean (SD) & $0.7(1.4)$ & $1.9(2.2)$ & $3.7(2.5)$ & $<0.001 \dagger$ & $<0.0019$ & $0.7(1.6)$ & $1.5(2.2)$ & $2.7(2.7)$ & $<0.001 \dagger$ & $<0.0019$ \\
\hline $\begin{array}{l}\text { Increase in IADL disability from wave } 2 \text { : at } \\
\text { least } 1 \text { point }(\%)\end{array}$ & 28.5 & 48.5 & 57.9 & $<0.001 \ddagger$ & $<0.001 \S$ & 22.2 & 39.8 & 39.4 & $<0.001 \ddagger$ & $<0.001 \S$ \\
\hline \multicolumn{11}{|l|}{ Disability at wave 4: SHARE-FI } \\
\hline $\mathrm{N}$ from wave 2 & 510 & 836 & 204 & - & - & 793 & 361 & 68 & - & - \\
\hline Number of limitations with BADL: mean (SD) & $0.3(0.7)$ & $0.8(1.2)$ & $1.6(1.5)$ & $<0.001 \dagger$ & $<0.0019$ & $0.4(0.9)$ & $0.8(1.3)$ & $1.2(1.5)$ & $<0.001 \dagger$ & $<0.001 \rrbracket$ \\
\hline $\begin{array}{l}\text { Increase in BADL disability from wave } 2 \text { : at } \\
\text { least } 1 \text { point }(\%)\end{array}$ & 17.8 & 30.9 & 44.1 & $<0.001 \ddagger$ & $<0.001 \S$ & 18.2 & 32.7 & 35.3 & $<0.001 \ddagger$ & $<0.001 \S$ \\
\hline Number of limitations with IADL: mean (SD) & $0.6(1.3)$ & $1.4(1.9)$ & $2.9(2.2)$ & $<0.001 \dagger$ & $<0.0019$ & $0.7(1.6)$ & $1.3(2.1)$ & $2.5(2.4)$ & $<0.001 \dagger$ & $<0.0019$ \\
\hline $\begin{array}{l}\text { Increase in IADL disability from wave } 2 \text { : at } \\
\text { least } 1 \text { point }(\%)\end{array}$ & 24.7 & 41.0 & 52.5 & $<0.001 \ddagger$ & $<0.001 \S$ & 23.7 & 34.1 & 47.1 & $<0.001 \ddagger$ & $<0.001 \S$ \\
\hline \multicolumn{11}{|c|}{ Two-tailed $z$ test for comparison of group proportions (SHARE-FI75+ vs SHARE-FI) } \\
\hline \multirow[t]{2}{*}{ 2-year mortality } & z 0.67 & 1.13 & 1.59 & - & - & -0.12 & 1.70 & 0.29 & - & - \\
\hline & p 0.503 & 0.258 & 0.112 & - & - & 0.904 & 0.091 & 0.772 & - & - \\
\hline \multirow[t]{2}{*}{ 4-year disability: at least $1 \mathrm{BADL}$ increase } & z 0.22 & 3.60 & 0.95 & - & - & -0.24 & 0.30 & 0.38 & - & - \\
\hline & p 0.826 & $<0.001$ & 0.342 & - & - & 0.810 & 0.764 & 0.704 & - & - \\
\hline 4-year disability: at least 1 & z 1.47 & 2.94 & 1.03 & - & - & -0.66 & 1.65 & -0.90 & - & - \\
\hline IADL increase & p 0.142 & 0.003 & 0.303 & - & - & 0.509 & 0.099 & 0.368 & - & - \\
\hline \multicolumn{11}{|c|}{$\begin{array}{l}\text { Significant } p \text { values }(<0.01) \text { are indicated in bold. } \\
\text { Model 3: adjusted by age, number of chronic diseases and number of limitations with BADL. } \\
\text { "Wald statistic. } \\
\dagger \text { Two-tailed Spearman's } r \text { test. } \\
\ddagger \chi^{2} \text { for trend. } \\
\text { SOrdinal regression. } \\
\text { १Partial correlation. }\end{array}$} \\
\hline
\end{tabular}


Table 3 Comparison of baseline characteristics between wave 2 participants with and without mortality data available (women)

\begin{tabular}{|c|c|c|c|}
\hline & $\begin{array}{l}\text { Mortality data } \\
\text { available }(\mathrm{N}=2402)\end{array}$ & $\begin{array}{l}\text { Mortality data not } \\
\text { available }(\mathrm{N}=923)\end{array}$ & $\begin{array}{l}\text { Significance of the } \\
\text { difference }(p)\end{array}$ \\
\hline \multicolumn{4}{|l|}{ Frailty variables } \\
\hline Fatigue: yes (\%) & 48.3 & 52.0 & $0.038^{*}$ \\
\hline Low appetite: yes (\%) & 16.7 & 15.7 & $0.477^{\star}$ \\
\hline Weakness: yes (\%) & 59.3 & 64.4 & $0.003^{\star}$ \\
\hline Observed walking without help (\%) & 73.3 & 63.4 & $<0.001^{*}$ \\
\hline Observed walking with help (\%) & 16.4 & 21.5 & $<0.001^{*}$ \\
\hline Observed in wheelchair/bedbound (\%) & 4.2 & 4.6 & $0.622^{*}$ \\
\hline Gait not observed (\%) & 6.1 & 10.5 & $<0.001^{*}$ \\
\hline Low activity: hardly ever, or never (\%) & 31.5 & 36.1 & $0.006^{\star}$ \\
\hline \multicolumn{4}{|l|}{ Frailty categories } \\
\hline Non-frail (\%) & 38.6 & 30.0 & $<0.001^{*}$ \\
\hline Prefrail (\%) & 45.5 & 48.4 & $0.124^{*}$ \\
\hline Frail (\%) & 15.9 & 21.6 & $<0.001^{*}$ \\
\hline \multicolumn{4}{|l|}{ Sociodemographic } \\
\hline Age: mean (SD) & $80.9(4.9)$ & $81.5(5.1)$ & $0.001 \dagger$ \\
\hline No more than primary education (\%) & 55.5 & 56.4 & $0.735^{\star}$ \\
\hline \multicolumn{4}{|l|}{ Physical } \\
\hline Poor self-rated health (\%) & 21.1 & 22.5 & $0.324^{*}$ \\
\hline Number of chronic diseases: mean (SD) & $2.5(1.7)$ & $2.4(1.7)$ & $0.052 \dagger$ \\
\hline Number of symptoms: mean (SD) & $3.0(2.4)$ & $2.7(2.3)$ & $0.011 \dagger$ \\
\hline Number of contacts with doctor in past year: mean (SD) & $9.0(10.8)$ & $9.1(11.1)$ & $0.777 \dagger$ \\
\hline Admitted to hospital in past year (\%) & 79.3 & 77.6 & $0.267^{\star}$ \\
\hline \multicolumn{4}{|l|}{ Functional } \\
\hline Number of limitations with BADL: mean (SD) & $0.7(1.4)$ & $0.7(1.4)$ & $0.685 \dagger$ \\
\hline Number of limitations with IADL: mean (SD) & $1.2(1.9)$ & $1.3(1.9)$ & $0.020 \dagger$ \\
\hline Received home care: personal/nursing (\%) & 10.6 & 11.4 & $0.497^{*}$ \\
\hline Received home care: domestic tasks (\%) & 17.3 & 19.6 & $0.112^{*}$ \\
\hline \multicolumn{4}{|l|}{ Psychological and cognitive } \\
\hline EURO-D score (minimum: 0; maximum: 12) (SD) & $3.2(2.6)$ & $3.3(2.6)$ & $0.426 \dagger$ \\
\hline Verbal fluency test score: mean (SD) & $15.0(7.6)$ & $13.4(6.5)$ & $<0.001 \dagger$ \\
\hline Delayed word recall score: mean (SD) & $2.4(1.9)$ & $2.2(1.9)$ & $0.015 \dagger$ \\
\hline
\end{tabular}

On the other hand, one could have added more subvariables for the other frailty phenotype variables in order to improve the prediction, but this was not attempted in our study. However, with regard to the variables included in a frailty index, it has been suggested that they can be coded either as dichotomous or ordinal, with a negligible impact on the performance of the index in predicting mortality. ${ }^{68}$

The prevalences of frailty as per SHARE-FI75+ (women: $36 \%$ non-frail, $46 \%$ prefrail, $18 \%$ frail; men: $47 \%$ non-frail, $41 \%$ prefrail, $12 \%$ frail) are consistent with the epidemiological literature; in a previous systematic review based on 21 cohorts involving 61500 participants, the prevalence of frailty was shown to increase with age and it was $15.7 \%$ in those aged $80-84 .^{3}$ Consistently, epidemiological studies have shown higher prevalence of frailty (and prefrailty) in women than in men. ${ }^{3}$ Conversely, the mortality associated with frailty is known to be higher in men than in women, ${ }^{69} 70$ and this was also the case with SHARE-FI75+ (women: $2 \%$ non-frail, $5 \%$ prefrail, $13 \%$ frail; men: $4 \%$ non-frail, $9 \%$ prefrail, $26 \%$ frail).

SHARE-FI75+ might be more feasible than SHARE-FI ${ }^{32}$ for implementation in primary care practice, because handgrip strength (a component of SHARE-FI) is not typically assessed in primary care and can add a few minutes to an assessment. ${ }^{36}$ In contrast, a busy primary care practitioner will be able to score the observed gait component of SHARE-FI75+ as soon as the patient enters through the door, which mirrors a very natural practice in geriatric assessment. ${ }^{71} 72$ Furthermore, by including the 'unobserved' category in the gait scoring scheme, SHARE-FI75+ may allow for the 'tele-assessment' of frailty (eg, provisional frailty scoring during telephone consultations). The potential practical advantages of SHARE-FI75+ over SHARE-FI are not offset by an inferior risk prediction; indeed, SHARE-FI75+ had a similar ability to predict 2-year 
Table 4 Comparison of baseline characteristics between wave 2 participants with and without mortality data available (men)

\begin{tabular}{|c|c|c|c|}
\hline & $\begin{array}{l}\text { Mortality data } \\
\text { available }(\mathrm{N}=1907)\end{array}$ & $\begin{array}{l}\text { Mortality data not } \\
\text { available }(\mathrm{N}=680)\end{array}$ & $\begin{array}{l}\text { Significance of the } \\
\text { difference }(p)\end{array}$ \\
\hline \multicolumn{4}{|l|}{ Frailty variables } \\
\hline Fatigue: yes (\%) & 38.0 & 41.1 & $0.135^{\star}$ \\
\hline Low appetite: yes (\%) & 11.4 & 13.4 & $0.133^{*}$ \\
\hline Weakness: yes (\%) & 38.0 & 40.3 & $0.254^{*}$ \\
\hline Observed walking without help (\%) & 79.1 & 74.1 & $0.006^{*}$ \\
\hline Observed walking with help (\%) & 11.0 & 12.4 & $0.328^{*}$ \\
\hline Observed in wheelchair/bedbound (\%) & 3.3 & 3.4 & $0.939^{*}$ \\
\hline Gait not observed (\%) & 6.6 & 10.1 & $0.002^{\star}$ \\
\hline Low activity: hardly ever, or never (\%) & 22.2 & 25.2 & $0.094^{*}$ \\
\hline \multicolumn{4}{|l|}{ Frailty categories } \\
\hline Non-frail (\%) & 48.3 & 42.8 & $0.013^{*}$ \\
\hline Prefrail (\%) & 39.6 & 44.6 & $0.024^{\star}$ \\
\hline Frail (\%) & 12.1 & 12.6 & $0.689^{*}$ \\
\hline \multicolumn{4}{|l|}{ Sociodemographic } \\
\hline Age: mean (SD) & $80.2(4.5)$ & $80.8(4.7)$ & $0.003 \dagger$ \\
\hline No more than primary education (\%) & 42.2 & 47.2 & $0.105^{\star}$ \\
\hline \multicolumn{4}{|l|}{ Physical } \\
\hline Poor self-rated health $(\%)$ & 17.1 & 20.2 & $0.053^{*}$ \\
\hline Number of chronic diseases: mean (SD) & $2.1(1.6)$ & $2.1(1.6)$ & $0.832 \dagger$ \\
\hline Number of symptoms: mean (SD) & $2.1(2.0)$ & $2.1(2.0)$ & $0.692 \dagger$ \\
\hline Number of contacts with doctor in past year: mean (SD) & $8.3(9.9)$ & $8.6(12.2)$ & $0.295 \dagger$ \\
\hline Admitted to hospital in past year (\%) & 79.8 & 75.7 & $0.015^{\star}$ \\
\hline \multicolumn{4}{|l|}{ Functional } \\
\hline Number of limitations with BADL: mean (SD) & $0.5(1.2)$ & $0.5(1.3)$ & $0.033 \dagger$ \\
\hline Number of limitations with IADL: mean (SD) & $0.8(1.7)$ & $0.9(1.7)$ & $0.046 \dagger$ \\
\hline Received home care: personal/nursing (\%) & 7.4 & 6.6 & $0.446^{*}$ \\
\hline Received home care: domestic tasks (\%) & 8.8 & 10.0 & $0.340^{*}$ \\
\hline \multicolumn{4}{|l|}{ Psychological and cognitive } \\
\hline EURO-D score (minimum: 0; maximum: 12) (SD) & $2.3(2.3)$ & $2.6(2.4)$ & $0.040 \dagger$ \\
\hline Verbal fluency test score: mean (SD) & $15.8(7.0)$ & $15.1(6.4)$ & $0.020 \dagger$ \\
\hline Delayed word recall score: mean (SD) & $2.3(1.8)$ & $2.2(1.8)$ & $0.613 \dagger$ \\
\hline
\end{tabular}

mortality and 4-year disability, and even a greater ability to predict 4-year disability in prefrail women. An additional advantage of SHARE-FI75+ is that three additional European countries are represented in its validation: Czechia, Poland and Ireland (these countries were not included in the development of SHARE-FI ${ }^{32}$ ).

From the comparative analyses for incident mortality presented in figures 4 and 5 , one could conclude that all these tools have very similar performances, in keeping with the increasingly recognised principle that rather than being mutually exclusive, different frailty definition approaches are complementary and suitable for different purposes or scenarios. ${ }^{25}$

Another potential advantage of the SHARE-FI75+ calculator is that it generates age-adjusted results, while the previous SHARE-FI calculator does not. Thus, the SHARE-FI75+ is more in keeping with frailty being an age-independent marker of risk, ${ }^{73}$ closer to the concept of biological (as opposed to chronological) age. ${ }^{74}$ In addition, an age-adjusted method for frailty screening may be more sensitive in younger ages and more specific in older ages, benefiting the purpose of population screening. ${ }^{75}$ The continuous, age-adjusted SHARE-FI75+ score values range from 0 to 1 , making it a much more intuitive score than the age-unadjusted one given by SHARE-FI $(-4$ to 6$) .{ }^{32}$

A general limitation of SHARE-FI75+ (which also applied to SHARE-FI) is that, despite being inspired on the frailty phenotype theory by Fried $e t a l,{ }^{26}$ some of the SHARE items that compose the measure have departures from Fried's theoretical framework, namely as regards 'weight loss' (replaced by low appetite), and 'weakness' and 'slowness' (measured by functional limitations). Thus, compared with the original frailty phenotype, SHARE-FI75 + may capture people at a more advanced stage of the disablement process. Nevertheless, for the validation of SHARE-FI75+, the functional limitations questions composing the measure were not included in the disability outcomes; this suggests that SHARE-FI75+ still captures a predisability state, in 


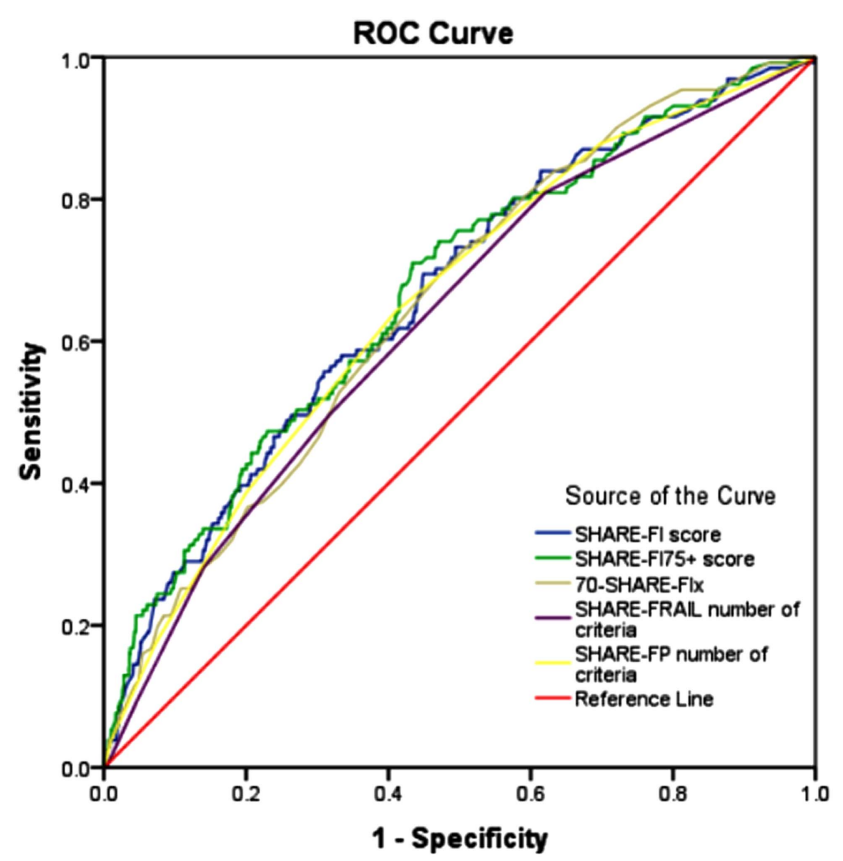

Figure 4 Receiver operating characteristic (ROC) curves comparing the mortality prediction by the Frailty Instrument for Primary Care of the Survey of Health, Ageing and Retirement in Europe (SHARE-FI)75+, SHARE-FI, 70-SHARE-FIx, SHARE-FRAIL and SHARE-FP continuous scores (women). Areas under the curve (AUC; 95\% Cl) were: SHARE-Fl75+: 0.67 (0.62 to 0.72), $p<0.001$; SHARE-FI: 0.66 (0.62 to 0.71 ), $p<0.001$; 70-SHARE-FIx: 0.65 (0.61 to 0.70), $p<0.001$; SHARE-FRAIL: 0.63 (0.58 to 0.68 ), $p<0.001$; SHARE-FP: 0.65 (0.61 to 0.70$), p<0.001$.

keeping with the frailty phenotype theory. ${ }^{28}$ SHARE-FI was also modelled as a vulnerability state prior to the onset of more severe activity limitation. ${ }^{69}$

Another limitation of this study is that, owing to the high proportion of missing data for the walking speed test in SHARE (50\% in women and $44 \%$ in men), this variable could not reliably be used for the construction of SHARE-FI75+. Instead, the observed respondent status (which had lower proportions of missing data, $12 \%$ in women and $13 \%$ in men) was used as a surrogate walking speed criterion. Nevertheless, it is known that performance-based assessments in surveys have more variable missingness, which suggests that their implementation in clinical practice may be less feasible. ${ }^{34}$ The fact that missing mortality data were associated with being older and more frail suggests that in reality, the frailty-associated mortality rates may be higher than the ones estimated by this study. Other researchers have shown that death and incapacity are likely to be important sources of non-response in the SHARE data. ${ }^{76}$

A potential limitation our study is that we developed the SHARE-FI75+ algorithm using the whole sample, and we did not check the differences of the algorithm for each country. This is because the sample sizes for each individual country, once stratified by gender, are

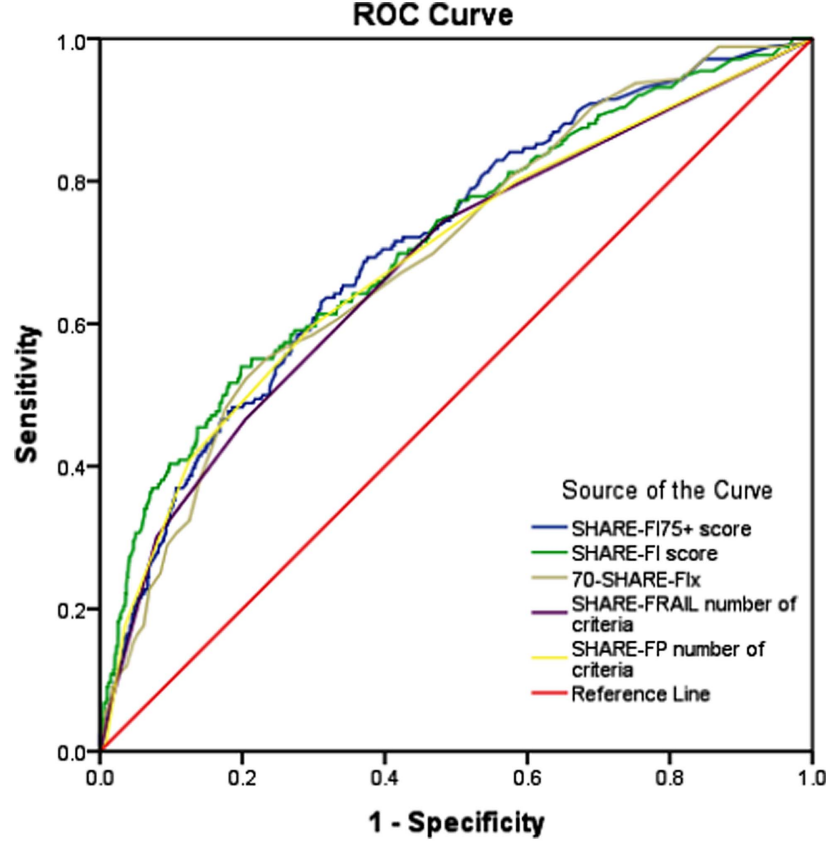

Figure 5 Receiver operating characteristic (ROC) curves comparing the mortality prediction by the Frailty Instrument for Primary Care of the Survey of Health, Ageing and Retirement in Europe (SHARE-FI)75+, SHARE-FI, 70-SHARE-FIx, SHARE-FRAIL and SHARE-FP continuous scores (men). Areas under the curve (AUC; $95 \% \mathrm{Cl}$ ) were: SHARE-FI75+: 0.71 (0.67 to 0.75 ), $p<0.001$; SHARE-FI: 0.71 (0.67 to 0.76 ), $p<0.001$; 70-SHARE-FIx: 0.70 (0.66 to 0.74), $p<0.001$; SHARE-FRAIL: 0.68 (0.64 to 0.72), p<0.001; SHARE-FP: 0.69 (0.65 to 0.73 ), $p<0.001$.

relatively small for those analyses. In that light, a previous study with SHARE-FI (which focused on the larger population aged $\geq 50$ years) showed that the relationships between the construct of frailty and indicators, although broadly constant, do vary across some countries; furthermore, there was evidence of differing levels of frailty for the middle-aged and older populations across European countries. ${ }^{33}$

SHARE-FI75+ should be seen as a frailty assessment tool rather than a frailty screening tool. In fact, with the WHO screening criteria in mind, the 2013 draft report for the UK National Screening Committee concluded that at present there is insufficient evidence to support the implementation of systematic screening in old age to prevent hospitalisation and/or early death; however, the report also highlighted areas for further research, including the identification of measurement tools (including frailty assessment tools), which are the best predictors of adverse outcomes in community-dwelling older people. ${ }^{19}$

For policymakers, SHARE-FI75+ may represent an easy to implement tool which focuses on one of the fastest growing sectors of the population, ${ }^{5}$ including the biggest users of health and social care. ${ }^{76}$ An age-independent risk assessment may not only promote equity of access to specialist CGA services, but also help avoid age 
discrimination in the provision of health and social care services. ${ }^{17}$ The identification of frailty as a predisability condition may allow for preventative interventions against disability ${ }^{77} 78$ and facilitate a paradigm of personalised medicine in old age. ${ }^{79}$

We would suggest that SHARE-FI75+ is not used in people younger than 75 years, since its validation was carried out on the SHARE samples aged 75 or more. In addition, if someone wants to use the SHARE-FI75+ calculator to classify a participant's frailty level but does not have all five variables, SHARE-FI75+ should not be used, as it may lose clinical accuracy.

Many frailty identification tools exist that may be suitable for primary care, ${ }^{37-39}{ }^{80}$ but at present none can be identified as 'the best'. Although successful experiences have been reported from clinical trials with some frailty tools, ${ }^{3081}$ the use of other tools (such as the Groningen Frailty Indicator ${ }^{82}$ ) has been shown to be not more effective than usual care in reducing disability and preventing further functional decline in communitydwelling older people. In that regard, the effectiveness of SHARE-FI75+ will have to be tested in similar research studies.

Meanwhile, in response to a strong policy drive for integration of health and social care services, the National Health Service (NHS) in England has recently recommended that incentives be developed that encompass the systematic screening for frailty in people above the age of 75 in primary care and the creation of registers of frail older people. ${ }^{48}$ In its recent draft guidance, NICE recommends that local authorities and health and social care providers should use routine appointments and contacts to identify people at risk of frailty, give them advice on how to reduce the risks and refer people to specialist services when necessary. ${ }^{21}$ While these innovative, quality improvement-driven programmes are still at an early developmental stage, they will allow for the real-life piloting of new frailty assessment tools (such as SHARE-FI75+), and their future evaluation will provide a valuable complement to the evidence emerging from research studies.

\section{Author affiliations \\ ${ }^{1}$ Department of Medicine for the Elderly (DME), Addenbrooke's Hospital, Cambridge University Hospitals NHS Foundation Trust, Cambridge, UK ${ }^{2}$ Clinical Gerontology Unit, Department of Public Health and Primary Care, University of Cambridge, Addenbrooke's Hospital, Cambridge, UK ${ }^{3}$ Department of Medical Physics and Bioengineering, St. James's Hospital, Dublin, Ireland \\ ${ }^{4}$ Mercer's Institute for Successful Ageing, St. James's Hospital, Dublin, Ireland.}

Contributors All coauthors satisfy the recommendations outlined in the ICMJE Recommendations 2013. RR-0 conceived the work, performed the statistical analyses, drafted the manuscript and approved the final version to be published; he is the guarantor for the study. CS substantially contributed to the design of the work (frailty calculator), revised the manuscript critically for important intellectual content and approved the final version to be published. All authors had full access to all of the data (including statistical reports and tables) in the study and can take responsibility for the integrity of the data and the accuracy of the data analysis.
Funding This study was supported the European Commission, the US National Institute on Aging, and the German Ministry of Education and Research.

Competing interests None.

Ethics approval Ethics Committee of the University of Mannheim and the Ethics Council of the Max-Planck-Society for the Advancement of Science.

Provenance and peer review Not commissioned; externally peer reviewed.

Data sharing statement We undertook a secondary analysis of data obtained under the SHARE Data Access Rules (http://share-dev.mpisoc.mpg.de/ data-access-documentation/research-data-center-data-access.html). SHARE data can be accessed by anyone who abides by those rules.

Open Access This is an Open Access article distributed in accordance with the Creative Commons Attribution Non Commercial (CC BY-NC 4.0) license, which permits others to distribute, remix, adapt, build upon this work noncommercially, and license their derivative works on different terms, provided the original work is properly cited and the use is non-commercial. See: http:// creativecommons.org/licenses/by-nc/4.0/

\section{REFERENCES}

1. Clegg A, Young J, Iliffe S, et al. Frailty in elderly people. Lancet 2013;381:752-62.

2. Campbell AJ, Buchner DM. Unstable disability and the fluctuations of frailty. Age Ageing 1997;26:315-18.

3. Collard RM, Boter H, Schoevers RA, et al. Prevalence of frailty in community-dwelling older persons: a systematic review. J Am Geriatr Soc 2012;60:1487-92.

4. Zaidi A. Features and Challenges of Population Ageing: The European Perspective. Policy Brief March (1) 2008: European Centre for social Welfare Policy and Research; 2008.

5. Steptoe A, Breeze E, Banks J, et al. Cohort profile: the English Longitudinal Study of Ageing. Int J Epidemiol 2013;42:1640-8.

6. Lloyd-Sherlock P, McKee M, Ebrahim S, et al. Population ageing and health. Lancet 2012;379:1295-6.

7. Hebert R. Functional decline in old age. CMAJ 1997;157:1037-45.

8. Quinn TJ, McArthur K, Ellis G, et al. Functional assessment in older people. BMJ 2011;343:d4681.

9. Ward K, Reuben D. Comprehensive geriatric assessment UpToDate2013. http://www.uptodate.com/contents/comprehensivegeriatric-assessment.

10. Shamliyan T, Talley KM, Ramakrishnan R, et al. Association of frailty with survival: a systematic literature review. Ageing Res Rev 2013;12:719-36.

11. Frese $T$, Deutsch $T$, Keyser M, et al. In-home preventive comprehensive geriatric assessment (CGA) reduces mortality-a randomized controlled trial. Arch Gerontol Geriatr 2012:55:639-44.

12. Ellis G, Whitehead MA, Robinson D, et al. Comprehensive geriatric assessment for older adults admitted to hospital: meta-analysis of randomised controlled trials. BMJ 2011;343:d6553.

13. Alessi CA, Stuck AE, Aronow HU, et al. The process of care in preventive in-home comprehensive geriatric assessment. J Am Geriatr Soc 1997;45:1044-50.

14. Rubenstein $L Z$, Rhee $L$, Kane $R L$. The role of geriatric assessment units in caring for the elderly: an analytic review. J Gerontol 1982;37:513-21.

15. Lacas A, Rockwood K. Frailty in primary care: a review of its conceptualization and implications for practice. BMC Med 2012;10:4

16. De Lepeleire J, lliffe S, Mann E, et al. Frailty: an emerging concept for general practice. Br J Gen Pract 2009;59:e177-82.

17. Romero-Ortuno R, O'Shea D. Fitness and frailty: opposite ends of a challenging continuum! Will the end of age discrimination make frailty assessments an imperative? Age Ageing 2013;42:279-80.

18. Berrut G, Andrieu S, Araujo de Carvalho I, et al. Promoting access to innovation for frail old persons. IAGG (International Association of Gerontology and Geriatrics), WHO (World Health Organization) and SFGG (Societe Francaise de Geriatrie et de Gerontologie) Workshop-Athens January 20-21, 2012. J Nutr Health Aging 2013;17:688-93.

19. Dent M. Screening in old age to prevent hospitalization and death: a draft report for the UK National Screening Committee. Oxford: Solutions for Public Health, 2013. http://www.screening.nhs.uk/ policydb_download.php?doc $=268$

20. De Lepeleire J, Degryse J, Illiffe S, et al. Family physicians need easy instruments for frailty. Age Ageing 2008;37:484; author reply -5 . 
21. NICE. Public health draft guideline: dementia, disability and frailty in later life-mid-life approaches to prevention. London: National Institute for Health and Care Excellence, 2014. https://www.nice.org uk/guidance/gid-phg64/resources/disability-dementia-and-frailty-inlater-life-midlife-approaches-to-prevention-draft-guidance2

22. de Vries NM, Staal JB, van Ravensberg CD, et al. Outcome instruments to measure frailty: a systematic review. Ageing Res Rev 2011;10:104-14.

23. Jones DM, Song X, Rockwood K. Operationalizing a frailty index from a standardized comprehensive geriatric assessment. J Am Geriatr Soc 2004;52:1929-33.

24. Jones $\mathrm{D}$, Song $\mathrm{X}$, Mitnitski $\mathrm{A}$, et al. Evaluation of a frailty index based on a comprehensive geriatric assessment in a population based study of elderly Canadians. Aging Clin Exp Res 2005;17:465-71.

25. Cesari M, Gambassi G, van Kan GA, et al. The frailty phenotype and the frailty index: different instruments for different purposes. Age Ageing 2014;43:10-12.

26. Fried LP, Tangen CM, Walston J, et al. Frailty in older adults: evidence for a phenotype. J Gerontol A Biol Sci Med Sci 2001;56: M146-56.

27. Vermeulen J, Neyens JC, van Rossum E, et al. Predicting ADL disability in community-dwelling elderly people using physical frailty indicators: a systematic review. BMC Geriatr 2011;11:33.

28. Fried LP, Ferrucci L, Darer J, et al. Untangling the concepts of disability, frailty, and comorbidity: implications for improved targeting and care. J Gerontol A Biol Sci Med Sci 2004;59:255-63.

29. Bandeen-Roche K, Xue QL, Ferrucci L, et al. Phenotype of frailty: characterization in the women's health and aging studies. J Gerontol A Biol Sci Med Sci 2006;61:262-6.

30. Li CM, Chen CY, Li CY, et al. The effectiveness of a comprehensive geriatric assessment intervention program for frailty in communitydwelling older people: a randomized, controlled trial. Arch Gerontol Geriatr 2010;50(Suppl 1):S39-42.

31. Eckel SP, Bandeen-Roche K, Chaves PH, et al. Surrogate screening models for the low physical activity criterion of frailty. Aging Clin Exp Res 2011;23:209-16.

32. Romero-Ortuno R, Walsh CD, Lawlor BA, et al. A frailty instrument for primary care: findings from the Survey of Health, Ageing and Retirement in Europe (SHARE). BMC Geriatr 2010;10:57.

33. King-Kallimanis BL, Kenny RA, Savva GM. Factor structure for the frailty syndrome was consistent across Europe. J Clin Epidemiol 2014;67:1008-15.

34. Theou O, Brothers TD, Mitnitski A, et al. Operationalization of frailty using eight commonly used scales and comparison of their ability to predict all-cause mortality. J Am Geriatr Soc 2013;61:1537-51.

35. Romero-Ortuno R. The Frailty Instrument of the Survey of Health, Ageing and Retirement in Europe (SHARE-FI) predicts mortality beyond age, comorbidities, disability, self-rated health, education and depression. Eur Geriatr Med 2011;2:323-6.

36. Romero-Ortuno R, O'Shea D, Kenny RA. The SHARE frailty instrument for primary care predicts incident disability in a European population-based sample. Qual Prim Care 2011;19:301-9.

37. Morley JE, Vellas $\mathrm{B}$, van Kan GA, et al. Frailty consensus: a call to action. J Am Med Dir Assoc 2013;14:392-7.

38. Pialoux T, Goyard J, Lesourd B. Screening tools for frailty in primary health care: a systematic review. Geriatr Gerontol Int 2012:12:189-97.

39. Daniels L, Deckx L, Thompson M, et al. Horizon Scan Report 0026: Diagnostic Technology: screening instruments for frailty in primary care. Oxford: Primary Care Diagnostic Horizon Scanning Centre, 2012. http://madox.org/horizon-scanning-reports/20120026/ screening-instruments-for-frailty-in-primary-care

40. Ntholang $\mathrm{O}$, Kelly RE, Romero-Ortuno $\mathrm{R}$, et al. The role the frailty syndrome can play in advocacy and resource allocation for our ageing population - findings in a Dublin day hospital. J Frailty Aging 2014;3:21-4.

41. Romero Ortuno R, Tiernan C, Cogan L. The impact of frailty on postacute rehabilitation outcomes in older adults. J Frailty Aging 2014; in press.

42. Dorner TE, Luger E, Tschinderle J, et al. Association between nutritional status (MNA(R)-SF) and frailty (SHARE-FI) in acute hospitalised elderly patients. J Nutr Health Aging 2014;18:264-9.

43. Ferguson C, Inglis SC, Newton PJ, et al. Frailty and thromboprophylaxis prescription in heart failure and atrial fibrillation: preliminary findings from the Atrial Fibrillation And Stroke Thromboprophylaxis in hEart failuRe (AFASTER) cohort study. Global Heart 2014;9:e264.

44. Roberts HC, Denison HJ, Martin HJ, et al. A review of the measurement of grip strength in clinical and epidemiological studies: towards a standardised approach. Age Ageing 2011;40:423-9.
45. Mohd Hairi F, Mackenbach JP, Andersen-Ranberg K, et al. Does socio-economic status predict grip strength in older Europeans? Results from the SHARE study in non-institutionalised men and women aged 50+. J Epidemiol Community Health 2010;64:829-37.

46. Auyeung TW, Lee JS, Leung J, et al. The selection of a screening test for frailty identification in community-dwelling older adults. $J$ Nutr Health Aging 2014:18:199-203.

47. Schoon Y, Bongers K, Van Kempen J, et al. Gait speed as a test for monitoring frailty in community-dwelling older people has the highest diagnostic value compared to step length and chair rise time. Eur $J$ Phys Rehabil Med 2014. Published Online 31 July 2014.

48. NHS (England). Safe, compassionate care for frail older people using an integrated care pathway: Practical guidance for commissioners, providers and nursing, medical and allied health professional leaders. 2014. http://www.england.nhs.uk/wp-content/ uploads/2014/02/safe-comp-care.pdf.

49. Castell MV, Sanchez M, Julian R, et al. Frailty prevalence and slow walking speed in persons age 65 and older: implications for primary care. BMC Fam Pract 2013;14:86.

50. Abellan van Kan G, Rolland Y, Andrieu S, et al. Gait speed at usual pace as a predictor of adverse outcomes in community-dwelling older people an International Academy on Nutrition and Aging (IANA) Task Force. J Nutr Health Aging 2009;13:881-9.

51. Alcser KH, Benson G, Börsch-Supan A, et al. The Survey of Health, Aging, and Retirement in Europe-methodology. Mannheim Mannheim Research Institute for the Economics of Aging (MEA), 2005.

52. Borsch-Supan A, Brandt M, Hunkler C, et al. Data resource profile: the Survey of Health, Ageing and Retirement in Europe (SHARE). Int J Epidemiol 2013;42:992-1001.

53. Klevmarken A, Hesselius $P$, Swensson B. The SHARE sampling procedures and calibrated designs weights. In: Börsch-Supan A, Jürges $\mathrm{H}$, eds. The Survey of Health, Aging, and Retirement in Europe-methodology. Mannheim: Mannheim Research Institute for the Economics of Aging (MEA), 2005:28-69. http://wwwshareprojectorg/t3/share/fileadmin/pdf documentation/Methodology/ Methodology 2005pdf

54. Börsch-Supan A, Brugiavini $\mathrm{A}$, Jürges $\mathrm{H}$, et al. First results from the Survey of Health, Ageing and Retirement in Europe (2004-2007). Starting the longitudinal dimension. Mannheim: Mannheim Research Institute for the Economics of Aging (MEA), 2008

55. Börsch-Supan A, Brandt M, Litwin H, Weber G, eds. Active ageing and solidarity between generations in Europe: first results from SHARE after the economic crisis. Berlin: De Gruyter, 2013.

56. Malter F, Börsch-Supan A, eds. SHARE wave 4: innovations \& methodology. Munich: MEA, Max Planck Institute for Social Law and Social Policy, 2013.

57. Smith WN, Del Rossi G, Adams JB, et al. Simple equations to predict concentric lower-body muscle power in older adults using the 30-second chair-rise test: a pilot study. Clin Interv Aging 2010;5:173-80.

58. Börsch-Supan A, Jürges H, eds. The Survey of Health, Aging, and Retirement in Europe-methodology. Mannheim: Mannheim Research Institute for the Economics of Aging (MEA), 2005. http:// www.share-project.org/t3/share/fileadmin/pdf documentation/ Methodology/Methodology_2005.pdf

59. UoM. Interviewer Project Manual: Survey of Health, Ageing and Retirement in Europe: main test 2004. Michigan: Survey Research Center, University of Michigan's Institute for Social Research, 2004. http://www.share-project.org/new_sites/SHARE-Website/ Documentation/Interviewer\%20Project\%20Manual.pdf

60. UNESCO. International Standard Classification of Education (ISCED) 1997. Montreal: UNESCO Institute for Statistics, 2006 http://www.uis.unesco.org/Library/Documents/isced97-en.pdf

61. Katz S, Ford AB, Moskowitz RW, et al. Studies of illness in the aged The index of Adl: a standardized measure of biological and psychosocial function. JAMA 1963;185:914-19.

62. Lawton MP, Brody EM. Assessment of older people: self-maintaining and instrumental activities of daily living. Gerontologist 1969;9:179-86.

63. Castro-Costa E, Dewey M, Stewart R, et al. Ascertaining late-life depressive symptoms in Europe: an evaluation of the survey version of the EURO-D scale in 10 nations. The SHARE project. Int $J$ Methods Psychiatr Res 2008;17:12-29.

64. Theou O, Brothers TD, Pena FG, et al. Identifying common characteristics of frailty across seven scales. J Am Geriatr Soc 2014;62:901-6.

65. Abellan van Kan G, Rolland YM, Morley JE, et al. Frailty: toward a clinical definition. J Am Med Dir Assoc 2008;9:71-2.

66. Santos-Eggimann B, Cuenoud P, Spagnoli J, et al. Prevalence of frailty in middle-aged and older community-dwelling Europeans living in 10 countries. J Gerontol A Biol Sci Med Sci 2009;64:675-81. 
67. Romero-Ortuno R. The SHARE operationalized frailty phenotype: a comparison of two approaches. Eur Geriatr Med 2013;4:255-9.

68. Pena FG, Theou O, Wallace L, et al. Comparison of alternate scoring of variables on the performance of the frailty index. BMC Geriatr 2014;14:25.

69. Romero-Ortuno R, Fouweather T, Jagger C. Cross-national disparities in sex differences in life expectancy with and without frailty. Age Ageing 2014;43:222-8.

70. Hubbard RE, Rockwood K. Frailty in older women. Maturitas 2011;69:203-7.

71. Peel NM, Kuys SS, Klein K. Gait speed as a measure in geriatric assessment in clinical settings: a systematic review. J Gerontol A Biol Sci Med Sci 2013;68:39-46.

72. Nayak US, Gabell A, Simons MA, et al. Measurement of gait and balance in the elderly. J Am Geriatr Soc 1982;30:516-20.

73. Schuurmans $\mathrm{H}$, Steverink $\mathrm{N}$, Lindenberg $\mathrm{S}$, et al. Old or frail: what tells us more? J Gerontol A Biol Sci Med Sci 2004; 59:M962-5

74. Ries W, Pothig D. Chronological and biological age. Exp Gerontol 1984:19:211-16.

75. Romero-Ortuno R. An alternative method for Frailty Index cut-off points to define frailty categories. Eur Geriatr Med 2013;4:299-303.
76. Ilinca S, Calciolari S. The patterns of health care utilization by elderly Europeans: frailty and its implications for health systems. Health Serv Res 2014. Published Online 19 Aug 2014.

77. Vellas B, Balardy L, Gillette-Guyonnet S, et al. Looking for frailty in community-dwelling older persons: the Gerontopole Frailty Screening Tool (GFST). J Nutr Health Aging 2013;17:629-31.

78. Daniels $\mathrm{R}$, van Rossum E, de Witte $\mathrm{L}$, et al. Interventions to prevent disability in frail community-dwelling elderly: a systematic review. BMC Health Serv Res 2008;8:278.

79. Reynaud C, McHugh T, Romero Ortuno R. Frailty: what does it mean for clinical care provision? Scott Univ Med J 2014;3:54-64.

80. Drubbel I, Numans ME, Kranenburg G, et al. Screening for frailty in primary care: a systematic review of the psychometric properties of the frailty index in community-dwelling older people. BMC Geriatr 2014;14:27.

81. Bandinelli S, Lauretani F, Boscherini V, et al. A randomized, controlled trial of disability prevention in frail older patients screened in primary care: the FRASI study. Design and baseline evaluation. Aging Clin Exp Res 2006;18:359-66.

82. Metzelthin SF, van Rossum E, de Witte LP, et al. Effectiveness of interdisciplinary primary care approach to reduce disability in community dwelling frail older people: cluster randomised controlled trial. BMJ 2013;347:f5264. 